\title{
Relationships Between Near-Surface Plankton Concentrations, Hydrography, and Satellite-Measured Sea Surface Temperature
}

\author{
A. C. Thomas ${ }^{1}$ AND W. J. EMERY ${ }^{2}$ \\ Department of Oceanography, University of British Columbia, Vancouver, Canada
}

\begin{abstract}
In situ measurements of surface chlorophyll and zooplankton concentration are compared with in situ hydrographic measurements and infrared satellite images of the west coast of British Columbia for early winter and midsummer study periods. Maximum winter concentrations of chlorophyll $\left(1.0 \mathrm{mg} \mathrm{m}^{-3}\right)$ and zooplankton ( 2900 counts $\mathrm{m}^{-3}$ ) were found in colder, more stratified nearshore water. Warmer water over the middle and outer shelf consistently had the lowest chlorophyll and zooplankton concentrations ( $<0.2 \mathrm{mg} \mathrm{m}^{-3}$ and $<1700$ counts $\mathrm{m}^{-3}$, respectively). Correlations between winter $\log _{e}$ transformed zooplankton concentrations and surface temperature demonstrated that infrared satellite imagery explained $49 \%$ of the sampled zooplankton concentration variance. The winter association of specific chlorophyll concentrations with identifyable hydrographic regimes enabled the satellite imagery, in conjunction with an image-derived salinity model, to explain $55 \%$ of the sampled chlorophyll variance. Maximum summer chlorophyll concentrations $\left(>20.0 \mathrm{mg} \mathrm{m}^{-3}\right)$ coincided with intermediate temperatures around the edge of an upwelling frontal zone with lower concentrations $\left(\approx 5.0 \mathrm{mg} \mathrm{m}^{-3}\right)$ in the coldest, most recently upwelled water. Lowest concentrations $\left(<1.0 \mathrm{mg} \mathrm{m}^{-3}\right)$ were present in vertically stratified regions of the shelf. A least squares fit nonlinear equation showed that satellite-measured surface temperature patterns explained $72 \%$ of the $\log _{e}$ transformed chlorophyll variance. In contrast with the above relationships, summer zooplankton concentrations were not consistently related to satellite temperature patterns. While peaks showed a qualitative association with higher chlorophyll concentrations at the outer edge of the upwelling area, surface temperature was a poor predictor of zooplankton concentration over the study area as a whole.
\end{abstract}

\section{INTRODUCTION}

In the past, the mapping of plankton distributions and the development of models relating them to physical oceanographic processes, especially in complex and dynamic continental shell regions, have suffered from the unavoidable nonsynoptic nature of ship sampling. It is extremely difficult, especially with nonconservative biological variables, to separate spatial variability from temporal variability. Satellite infrared images of sea surface temperature (SST) provide a means of synoptically mapping and monitoring the surface signature of many of the physical processes which potentially have important biological implications. To the extent that plankton spatial patchiness is a response to physical processes, surface distributions of phytoplankton and zooplankton may be correlated with surface thermal features visible in satellite imagery. Satellite images of sea surface temperature may thus contain valuable information about the spatial and temporal distribution of surface plankton. In this paper we examine the extent to which satellite images of sea surface temperature reflect distributions of near-surface phytoplankton and zooplankton. Our purpose is not only to examine relationships between hydrographic properties and plankton concentrations but also to show simple, quantitative relationships between the cheap and readily available synoptic coverage of infrared satellite imagery and more expensive and, at best, quasisynoptic surface plankton measurements.

The importance of physical processes in determining the

\footnotetext{
'Now at College of Oceanography, Oregon State University, Corvallis.

${ }^{2}$ Now at Colorado Center for Atmospheric Research, University of Colorado, Boulder.
}

Copyright 1988 by the American Geophysical Union.

Paper number 88JC03322.

0148-0227/88/88JC-03322\$05.00 patterns and dominant spatial scales of biological variability was reviewed by Denman and Powell [1984], Legendre and Demers [1984], and Mackas et al. [1985]. Temperature has often been used as an indicator of the physical regime for comparison with plankton distributions [e.g., Denman and Platt, 1975; Denman, 1976; Fasham and Pugh, 1976; Fournier et al., 1979; Simpson et al., 1986], demonstrating that significant correlations exist between the thermal regime of the ocean and plankton distributions. These correlations can result from a direct biological response to temperature per se [e.g., Eppley, 1972], or more commonly from either direct interaction with mixing and advective processes or indirect interaction through trophic relationships [e.g., Lekan and Wilson, 1978; Steele and Henderson, 1979; Smith and Vidal, 1984].

Especially in dynamic areas, the synoptic perspective of infrared remote sensing has proved valuable in showing the spatial relationships between physical features and plankton distributions [Traganza et al., 1983; Abbott and Zion, 1985; Campbell and Esaias, 1985; Simpson et al., 1986]. These relationships have been shown to apply not only to chlorophyll distributions but also to zooplankton distributions [Wiebe et al., 1985; Haury et al., 1986; Boyd et al., 1986] and fish distributions [Breaker, 1981; Lasker et al., 1981; Laurs et al., 1984].

An early winter sampling period and a midsummer sampling period were used to investigate relationships between satellite-measured surface thermal patterns, hydrography, and in situ plankton distributions over the southern continental shelf off Vancouver Island, British Columbia. The study area and relevant bathymetry are shown in Figure 1. Thomas and Emery [1986] showed that patterns of winter chlorophyll and zooplankton concentration in this region were closely related to in situ hydrographic properties. The cross-shelf position of the northward flowing Davidson Current was correlated with regions of lower chlorophyll and zooplankton concentrations. 


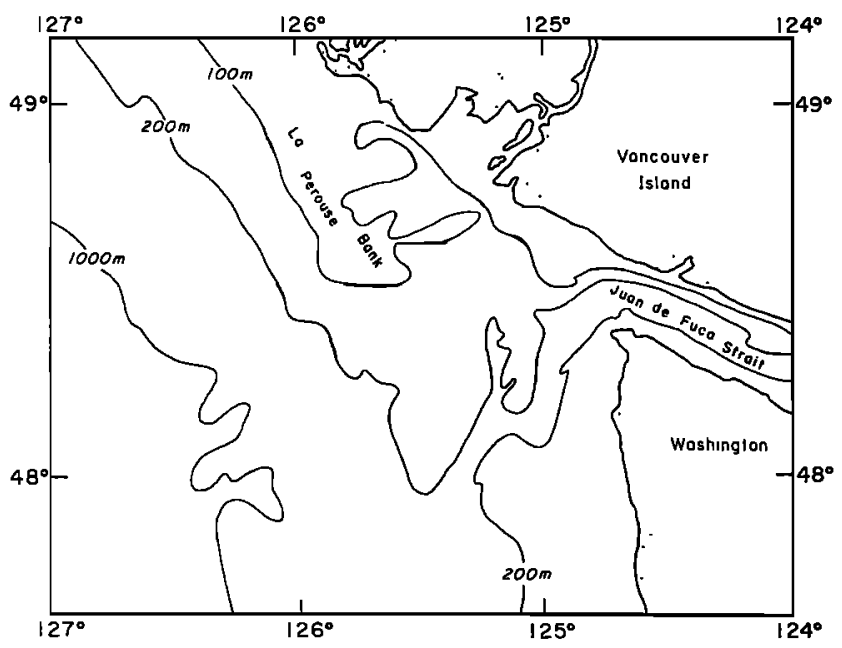

Fig. 1. The study area on the southern British Columbia continental shelf, showing bathymetry and relevant geographic features.

Colder and more stratified nearshore water was associated with higher plankton concentrations.

The summer southern British Columbia shelf is dominated by intense spatial and temporal patchiness of both phytoplankton and zooplankton biomass [Mackas et al., 1980; Denman et al., 1981; Mackas, 1984]. Dissimilarity correlograms calculated by Mackas [1984] showed that summer plankton patchiness patterns are stretched parallel to the bathymetry with cross-shell correlation scales one-third shorter than the alongshore scales. Satellite images of ocean color along the shelf edge demonstrate the patchy nature of the chlorophyll distribution and its general relationship to flow patterns [Thomson and Gower, 1985]. Mackas et al. [1980] and Denman et al. [1981] showed that summer zooplankton and phytoplankton concentrations were relatively high inshore of an alongshore salinity front, but lower seaward of this front, over the middle shelf. Localized peaks in phytoplankton and zooplankton biomass were present over both shallow banks and the outer shelf edge. Wind-driven upwelling is known to occur during the summer [Ikeda and Emery, 1984]. Freeland and Denman [1982], however, showed that the arrival of deep, nutrient rich water on the shelf is often uncoupled from the wind forcing. They argued that localized upwelling off the mouth of Juan de Fuca Strait is most likely associated with a topographically induced cyclonic eddy.

These previous studies have shown the southern British Columbia shelf to be physically dynamic and likely to have strong surface thermal gradients. Many of these processes and features are visible to infrared satellite imagery [e.g., Ikeda and Emery, 1984; Thomas and Emery, 1986; Emery et al., 1986]. The shelf also has a productive and heterogeneous plankton regime which these studies have shown to be closely coupled to the physical regime. This continental shelf region therefore provides a suitable location to examine relationships between infrared satellite imagery and plankton distributions.

\section{Data Collection and Processing}

Advanced very high resolution radiometer (AVHRR) satellite images of the west coast of British Columbia were received and processed at the University of British Columbia Satellite Oceanography Laboratory during two in situ sampling periods representing an early winter situation (November 28 to December 3,1983$)$ and a mid summer situation (July 10-18, 1984). Cloud-free weather along the British Columbia coast during both periods resulted in sequences of 10 infrared images of the study area for the winter sampling period and 15 infrared images for the summer sampling period. Raw satellite data were processed into navigated images of maximum spatial resolution ( 1 pixel $=1.1 \mathrm{~km}$ ) according to the procedure described by Emery and Ikeda [1983] using high-quality satellite ephemeris data supplied by the U.S. Navy. Final navigational accuracy was usually within one pixel over the entire image. Land- and cloud-contaminated pixels in each image were manually flagged. Attempts to use a split-window atmospheric correction [McClain, 1981] for these images resulted in an unacceptable increase in the spatial variance of the resultant temperature signal. This variance was most likely due to uncorrelated noise in channels 4 and 5. Although spatial filters would reduce this noise, they would also blur smallscale thermal patterns and gradients. In situ near-surface temperature measurements were used as ground truth data to provide the equivalent of an atmospheric correction for channel 4 of each satellite image. This assumes a horizontally homogeneous atmospheric attenuation which is likely to be valid over the relatively small study area, provided that pixels contaminated with cloud or fog are avoided. Ship measurements of surface temperature from cross-shelf transects were compared with satellite measurements from the same geographic locations and the least possible temporal separation (always less than 12 hours). A mean bias was calculated for each satellite image based on these transects and subtracted from the entire image to produce two temperature data sets of minimum root-mean-square difference. These mean biases $\left(t_{\text {ship }} t_{\text {channel } 4}\right)$ ranged between $2.3^{\circ}$ and $3.8^{\circ} \mathrm{C}$. Correlations between satellite- and ship-measured temperature along the transects used to make these corrections ranged between 0.901 and 0.992 (the number of observations ranged from 72 to 108).

Near-surface measurements of temperature, salinity, fluorescence, and zooplankton-sized particle abundance were made once per minute along a series of cross-shelf transects using a continuous flow, high-resolution, automated sampling system. The transects sampled during each cruise are shown in the next section, superimposed on concurrent satellite imagery. A detailed description of the apparatus and its use is given by Mackas et al. [1980] and will not be repeated here. Sampling depth was $1.5 \mathrm{~m}$ during the winter cruise, when the automated sampling system was linked to the ship's water intake and sea chest. Different plumbing aboard the summer research vessel did not allow a similar linkup, and water was sampled from $\approx 0.5 \mathrm{~m}$ through a towed hose $(\approx 8 \mathrm{~cm}$ internal diameter $)$ attached to a worm-gear pump. Flow rates through the automated sampler were $\approx 16 \mathrm{~L} \mathrm{~min}^{-1}$ and $\approx 13 \mathrm{~L} \mathrm{~min}^{-1}$ during the winter and summer, repectively. Logistics necessitated the use of a different prototype of the automated sampling system for the two sampling periods. Discrete samples were withdrawn from the sampling apparatus at half-hourly intervals and used for instrument calibration and later nutrient analysis. Fluorescence was converted to chlorophyll concentration by regression and was used as a measure of phytoplankton biomass. Particle counts were used as an estimation of zooplankton abundance. The instrument counts particles in the water presented to it in the size range $0.3-3.0 \mathrm{~mm}$. Although this is the smaller end of the zooplankton size spectrum, it does represent the numerically dominant portion of the population [Mackas et al., 1980]. The counts thus give a 
biased representation of total biomass distribution but a realistic estimate of the relative numbers of small zooplankton. Surface temperatures recorded during the winter cruise included a small but significant $\left(\approx 0.5^{\circ} \mathrm{C}\right)$ positive offset caused by warming in the ship's plumbing system [see Mackas et al., 1980]. This bias was constant; as emphasis in this study is on relative temperatures and spatial patterns, no attempt was made to correct for this offset.

At a cruising speed of approximately $18.5 \mathrm{~km} \mathrm{~h}^{-1}$, the spatial resolution of the near-surface in situ data was $\approx 300 \mathrm{~m}$. Obviously bad data points were first removed, and then the data record was averaged into $1-\mathrm{km}$ bins. This smoothing procedure eliminated small-scale structure but reduced the noise level, producing an in situ data set with a spatial resolution similar to that of the AVHRR data.

To reduce apparent spatial patchiness in the zooplankton data caused by diurnal vertical migrations, each of the winter transects, and each of the summer transects except part of leg 4, were sampled during daylight. Although night might have been a more effective time to sample, this portion of the cruises was utilized by other biological sampling.

Vertical temperature-salinity $(T-S)$ profiles were obtained with a Guildline conductivity-temperature-depth probe (CTD) at stations $18.5 \mathrm{~km}$ apart along each of the winter transects. Summer vertical temperature profiles were collected using an expendable bathythermograph (XBT). Summer station spacing was 9.25 and $18.5 \mathrm{~km}$ across shelf and $18.5 \mathrm{~km}$ along shelf. The geographic locations of these stations are given in the next section in relation to the concurrent satellite-measured surface thermal patterns.

Two approaches were used to quantify similarities between satellite-measured thermal patterns and plankton distributions. The first approach used a least squares approximation to define regression equations relating plankton concentrations with satellite surface temperature. The regression coeficients were then used to create a "plankton" image from the mean satellite temperature image and the relationship between image (modeled) concentrations and ship-measured concentrations used as a measure of similarity. The second approach expanded on relationships between specific plankton concentrations and hydrographic zones identified in temperature-salinity-plankton plots. Specific zones within each image were isolated by density slicing the thermal image at subjectively chosen thresholds. Each zone was then assigned the mean plankton concentration calculated from the in situ data points within the threshold boundaries and a "plankton" image created from these regions. The statistical relationship between modeled and measured concentrations was then calculated and used as a measure of similarity.

Three statistics were used to quantify the relationship between modeled and measured plankton concentrations. A root-mean-square (rms) difference between the two quantities provided a dimensional estimate of the model success in the same units as the treated data. The rms difference was defined as

$$
\mathrm{rmsdif}=\left[\frac{1}{N} \sum_{i=1}^{N}\left(x_{i}-\hat{x}_{i}\right)^{2}\right]^{1 / 2}
$$

where $x_{i}$ are the actual measured concentrations, $\hat{x}_{i}$ are the modeled values from the same locations in the "plankton" image, and $N$ is the number of data points. This statistic is equal to the standard deviation when the modeled value is the mean of the measured values (as it was within specific hydrographic regimes following the second modeling approach). Comparisons of model successes between the different units of chlorophyll and zooplankton concentration, and also between various normalizing transformations of the plankton data, were made with a dimensionless "error" term defined by normalizing the mean square difference by the original variance. Total model error was defined as

$$
\varepsilon^{2}=\frac{\sum\left(x_{i}-\hat{x}_{i}\right)^{2}}{\sum\left(x_{i}-\bar{x}\right)^{2}}
$$

where $\bar{x}$ is the mean of the measured plankton values and other terms are as previously defined. This term is the proportion of the original variance unexplained by the model, and the term

$$
r^{2}=\frac{\sum\left(\hat{x}_{t}-\bar{x}\right)^{2}}{\sum\left(x_{t}-\bar{x}\right)^{2}}
$$

is the proportion of the variance explained by the model. Both of these terms are nondimensional, and it can be seen that

$$
\varepsilon^{2}+r^{2}=1
$$

The number of degrees of freedom in these calculations is not easily defined. The statistics just defined incorporate both the large-scale field of variability (gradients larger than the length of the transects), which will not have been sampled in a statistically adequate manner, and smaller-scale variability (gradients shorter than the transects), which will have been sampled adequately. The number of data points used in these calculations was 461 and 453 respectively, for the winter and summer cruises. Each of these data points, however, cannot be considered independent [Mackas, 1984; Millard et al., 1985] owing to the short distance between them (high rate of sampling) relative to the length scales of oceanographic processes. The separation of the data points was $1 \mathrm{~km}$, considerably less than the $\approx 30 \mathrm{~km}$ length scales observed to dominate this region of the continental shelf by Denman and Freeland [1985]. For temperature and salinity, this spatial autocorrelation is a result of mixing associated with eddies, tidal advection, and other processes with length scales larger than 1 $\mathrm{km}$. The autocorrelation of chlorophyll and zooplankton is a result of interaction with these physical processes as well as biological processes, all of which induce well-known spatial patchiness.

The statistics utilize the total variability within the data. In the absence of a precise method of calculating the degrees of freedom associated with them, we first separate the larger- and smaller-scale variability and then present arguments for the degrees of freedom and/or significance of each.

\section{Winter and Summer Hydrographic Zonation}

\section{Satellite-Measured Surface Thermal \\ Patterns}

The sea surface temperature in each region of the winter shelf remained approximately constant over the period of in situ sampling. Furthermore, visual analysis of the winter satellite image series showed that the overall pattern of sea surface temperature remained nearly constant over the sampling period and that most of the interimage variability was at smaller scales (of the order of 5-10 km). The correlation of surface thermal patterns in the winter satellite image sequence 


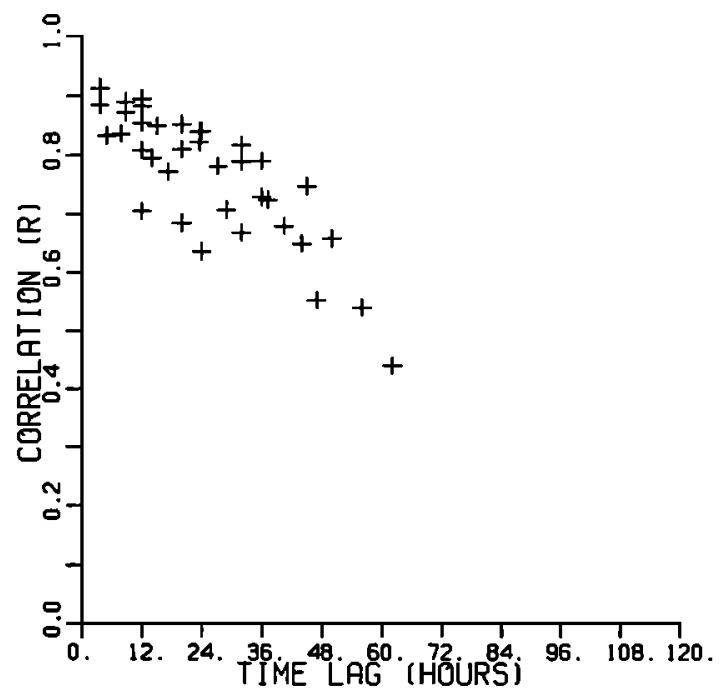

Fig. 2. Temporal correlation of winter surface thermal patterns in the study area calculated from correlations between all possible pairs of detrended satellite images.

over the sampling period is shown in Figure 2. Correlations were calculated between all possible pairs of images using image subsamples $(\approx 150 \times 150 \mathrm{~km})$ centered on the shelf study area and plotted as a function of their temporal separation. A large component of a simple correlation between images would be due to the dominant cross-shelf gradient in temperature which was present in each image. To isolate and examine underlying thermal patterns, this gradient was removed from each image subsample by calculating and subtracting the least squares fit plane (in $x, y, t^{\circ} \mathrm{C}$ space) of each image from itself. Correlation calculations shown in Figure 2 were then made on the residual thermal pattern.

The high correlation of thermal patterns over the winter study period permitted the nine image sequence to be reduced to a single mean image representing the surface thermal regime present during the winter cruise. This decision is supported by Denman and Freeland [1985], who concluded that surface thermal patterns on the British Columbia shelf over time periods of a single cruise $(\approx 10$ days) can be considered synoptic. Plate 1 shows the winter mean image calculated as the arithmetic mean of the nine most cloud-free images, with surface sampling transects and vertical stations superimposed. (Plate 1 can be found in the separate color section in this issue.) Only pixels which were cloud free in five or more images were used to calculate a mean temperature; pixels failing this criterion were classified as cloud.

The mean image shows the winter shelf could be divided into three major surface thermal zones. The dominant feature of this image is a region of warmest water over the middle and outer shelf, with temperatures above $12.2^{\circ} \mathrm{C}$ (warm zone). Maximum cross-shelf penetration of this warm water was in the southern portion of the study area, immediately south of La Perouse Bank. At La Perouse Bank the warm water curved offshore, away from the shelf. Coldest surface water was present as a continuous zone closest to shore, with temperatures below $11.5^{\circ} \mathrm{C}$ (cold zone). A distinct feature of this cold coastal zone was a tongue extending away from shore in a southward direction in the vicinity of La Perouse Bank. A frontal zone created by the strong surface thermal gradient separating cold coastal water from warmer water over the middle and outer shelf is visible in the image. Surface water seaward of the warmest band, over the outer shelf, formed a third thermal zone with intermediate temperatures of $11.6^{\circ} \mathrm{C}$ (offshore zone). Water seaward of this zone was colder $\left(11.0^{\circ} \mathrm{C}\right.$ in the satellite image) but was never sampled by the ship (see Plate 1). Although this water clearly formed another surface thermal zone, it will not be treated in this study, as no in situ data were available for comparison.

Visual analysis of the summer image series revealed signifcant changes in the overall surface thermal pattern in the study area over the period of in situ sampling. A mean image for the entire summer image series was therefore not meaningful, and all in situ data could not be considered synoptic. The correlation of summer surface thermal patterns in the study area over time (Figure 3) was calculated from detrended images in the same manner as the winter sequence.

Over time periods of less than 36 hours, surface patterns remained highly correlated. At separations starting at 24 hours, however, the range in correlation values began to increase. At 48 hours separation, correlations ranged from 0.72 to 0.38 . This reflects a short time scale "event" which rapidly

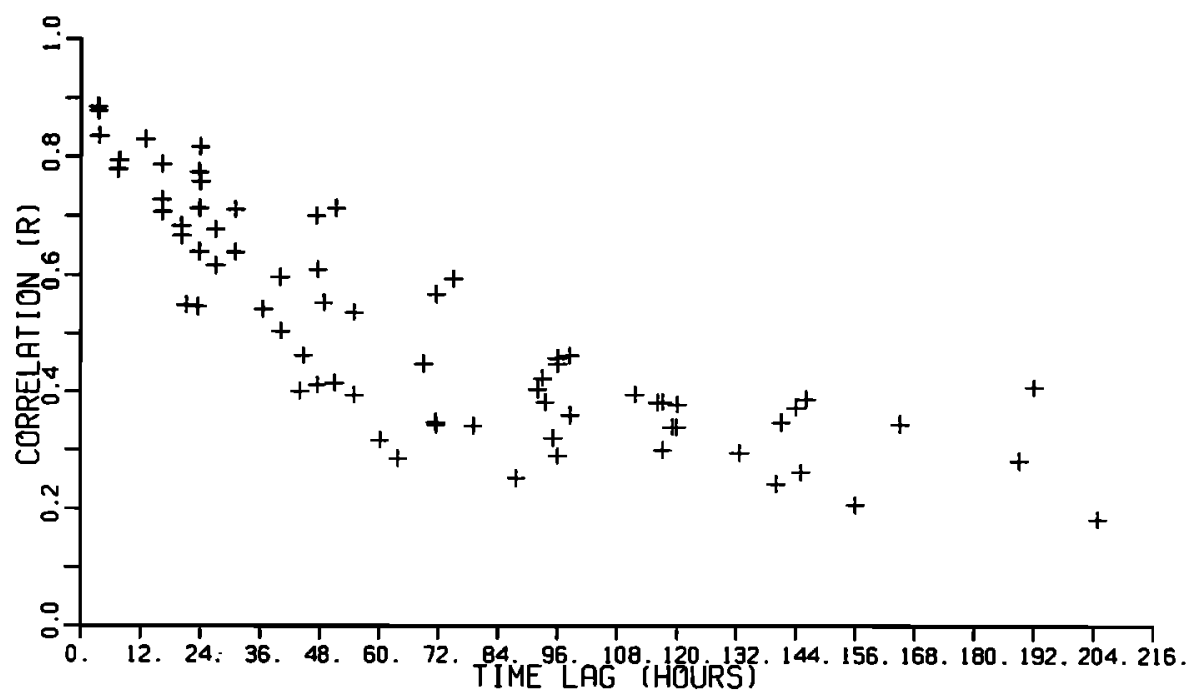

Fig. 3. Temporal correlation of summer surface thermal patterns in the study area calculated from correlations between all possible pairs of detrended satellite images. 
changed surface temperatures and patterns on July 16-17. Prior to this event, image patterns remained similar, and high correlations in Figure 3 extend to separations as long as 72 hours. Extrapolated structure functions from data averaged over 25 cruises [Denman and Freeland, 1985] show that nearsurface thermal patterns might be considered synoptic for time scales of less than 10 days. Although the satellite-measured surface skin temperature is probably less conservative than the integrated upper layers measured by these authors, data presented here suggest that specific events during the summer can make time scales of synopticity considerably shorter than this 10-day mean.

The summer image sequence was condensed into two representations for comparison with in situ plankton data. A mean image (Plate $2 a$ ) represents the arithmetic mean of the nine highly correlated images recorded prior to the cooling event on July 16-17. (Plate 2 can be found in the separate color section in this issue.) This image shows that the shelf area south of La Perouse Bank and over Juan de Fuca Canyon remained relatively cold throughout the study period, with thermal patterns retaining a generally circular shape (a cold zone). Mean surface temperatures in this region ranged from $11.5^{\circ}$ to $12.6^{\circ} \mathrm{C}$. The shelf areas seaward and also north of this region, over La Perouse Bank, were relatively warm during this early portion of the study period, with mean surface temperatures ranging from $13.5^{\circ}$ to $15.5^{\circ} \mathrm{C}$ (warm zone). The region over La Perouse Bank, however, cooled rapidly during the study period. The strong similarity of surface thermal patterns during the latter portion of the study period and those presented by Ikeda and Emery [1984] suggests that this cooling event was a wind-driven upwelling event. This is supported by unquantified observations from the ship of winds exceeding $10 \mathrm{~m} \mathrm{~s}^{-2}$ out of the northwest starting on July 15 . Bakum wind data for this period (B. M. Hickey et al., manuscript in preparation, 1988) show an increase in upwelling favorable winds during this period. In situ sampling during this cooling event was restricted to a single transect (leg 6). A single concurrent image (Plate $2 b$ ) is used to represent surface thermal patterns during this latter portion of the summer sampling period. This image shows the continued presence of the cold region off the mouth of Juan de Fuca Strait. North of this zone, however, the shelf is now dominated by colder surface water. A tongue of warmer water extends northward across the shelf, isolated by this colder water. This tongue was presumably a residual of the stratified warm water which had previously occupied this portion of the shelf (see Plate $2 a$ ).

\section{Surface and Subsurface Hydrography}

Contour plots of the spatial distribution of winter surface temperature and salinity presented by Thomas and Emery [1986] indicated the association of low temperatures with low salinities; they also showed this water to be restricted to the inner shelf and most pronounced off the mouth of Juan de Fuca Strait. Surface salinity distribution over the shelf increased from less than 30 in nearshore areas, to 32 over the outer shelf. A steep salinity gradient $(1.0$ in $4 \mathrm{~km})$ was coincident with the thermal front evident in the mean satellite image separating colder coastal regions from warmer regions over the middle shelf (Plate 1). The surface expression of the 31.5 isohaline extended furthest from shore in the La Perouse Bank area forming a low-salinity, low-temperature tongue. The thermal expression of this can be seen in the vicinity of the northern three transects (Plate 1).

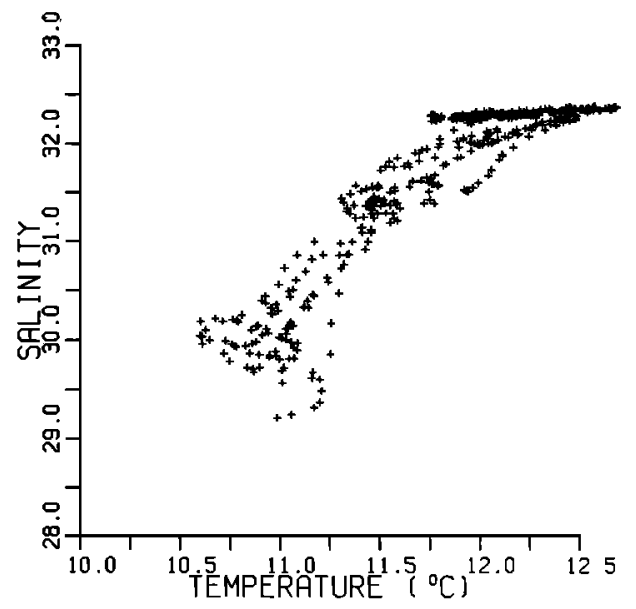

Fig. 4. Winter surface $T-S$ relationships from in situ sampled data (all transects).

Temperature-salinity plots of surface data from the water study period (Figure 4) show the hydrographic relationship of surface waters and support the surface zonation inferred from the satellite imagery. Nearshore water had the lowest temperatures $\left(<11.5^{\circ} \mathrm{C}\right)$ and salinities $(<31.5)$. Two types of surface water with higher salinities $(>32.0)$ can also be differentiated by temperature in the plots. Warmest temperatures in the study area were above $12.2^{\circ} \mathrm{C}$. A second high-salinity water type had temperatures between $11.5^{\circ} \mathrm{C}$ and $12.2^{\circ} \mathrm{C}$. Other T-S pairs form a line between coastal water characteristics and the warmest, high-salinity water, indicating that mixing and interaction between colder coastal water and the warmest water formed a major portion of sampled surface water over the winter shelf. Contours of subsurface temperature and salinity from legs 1 and 4 (Figure 5) show the inner-shelf colder, low salinity water was a near-surface feature. The warmest surface water visible in the satellite image was a distinct core of warm water $\left(<11.5^{\circ} \mathrm{C}\right)$ over the middle and outer shelf.

Thomas and Emery [1986] identified the zone of relatively warm water over the outer shelf visible in both satellite imagery and in vertical profiles of temperature as the northward flowing Davidson Current which Ikeda et al. [1984] identified in winter infrared imagery of the same area. The shallow, cold, and relatively fresh water near shore is indicative of estuarine influence from Juan de Fuca Strait and/or coastal rivers. The colder regions visible in the satellite imagery therefore represent the buoyancy-driven Vancouver Island Coastal Current [Freeland et al., 1984; also, B. M. Hickey et al., manuscript in preparation, 1988]. Vertical profiles identify these regions as the most strongly stratified areas of the shelf during the winter. The satellite imagery documents the extension and isolation of coastal current water out over the shelf in the vicinity of La Perouse Bank.

Regions of large surface temperature gradient, identified in the imagery (Plate 1), were coincident with large salinity gradients [Thomas and Emery, 1986] and formed a frontal zone separating Vancouver Island Coastal Current water from Davidson Current water. Water seaward of the Davidson Current had a similar high salinity but lower temperatures and is termed offshore water in this study. This water represents the most oceanic of the water types sampled during the winter study period.

The summer T-S plot (Figure 6a) of surface characteristics prior to the cooling event shows a general trend of colder 


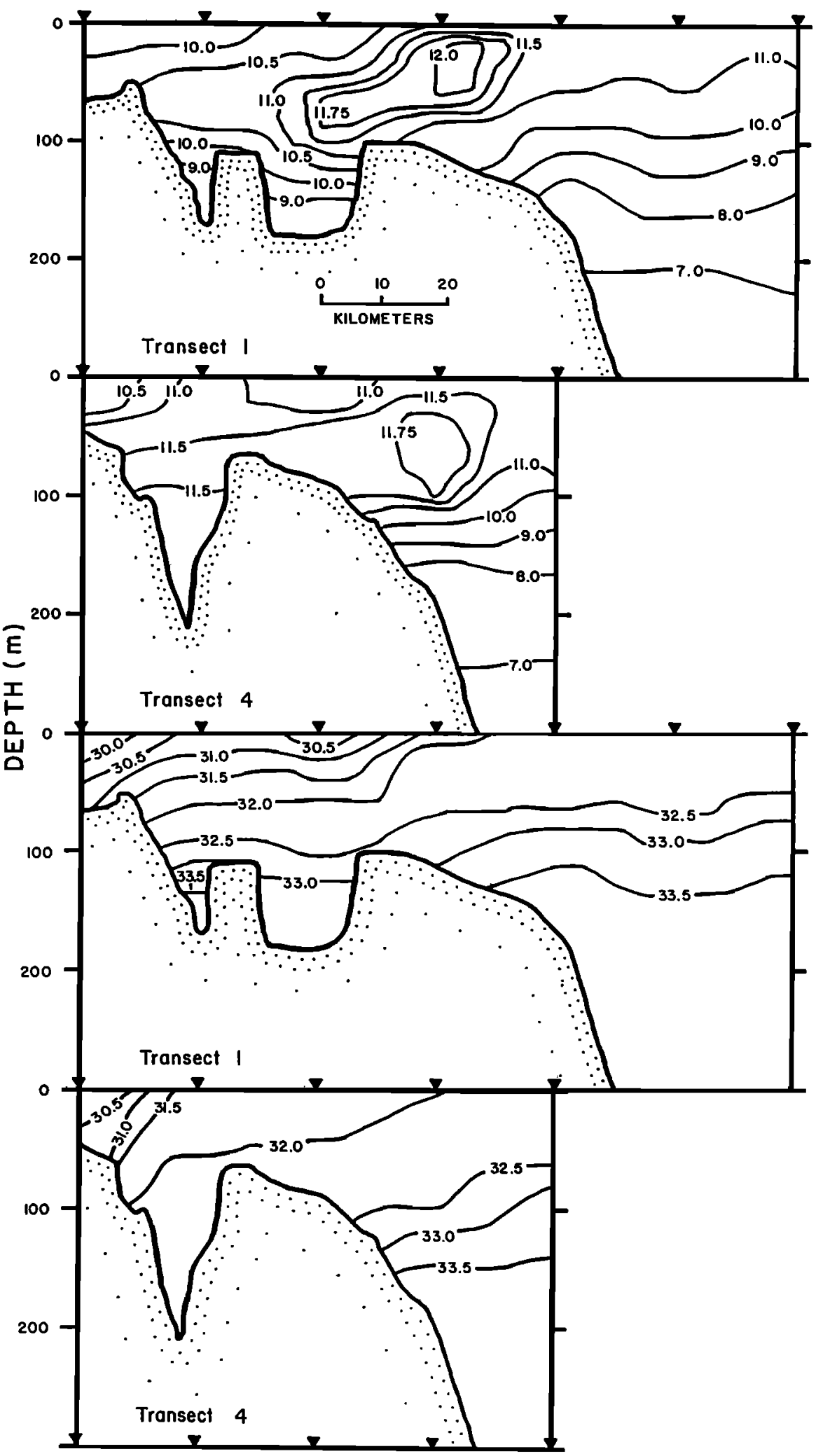

Fig. 5. Cross-shelf contours of winter subsurface temperature and salinity from stations along transects 1 and 4 . Triangles represent station locations, also shown in Plate 1. Depth is in meters.

temperatures associated with higher salinities but does not give a clear definition of water masses and mixing trends. This is most likely due to strong summer solar heating of surface water, which would change the relationship between surface temperature and salinity over relatively short time periods.
Surface temperatures in this region are likely to be more variable in the summer than in winter, when air-sea temperature differences are small and solar heating is minimal. $T-S$ characteristics of surface water during the cooling event (Figure $6 b$ ) indicate that although surface temperature patterns have 

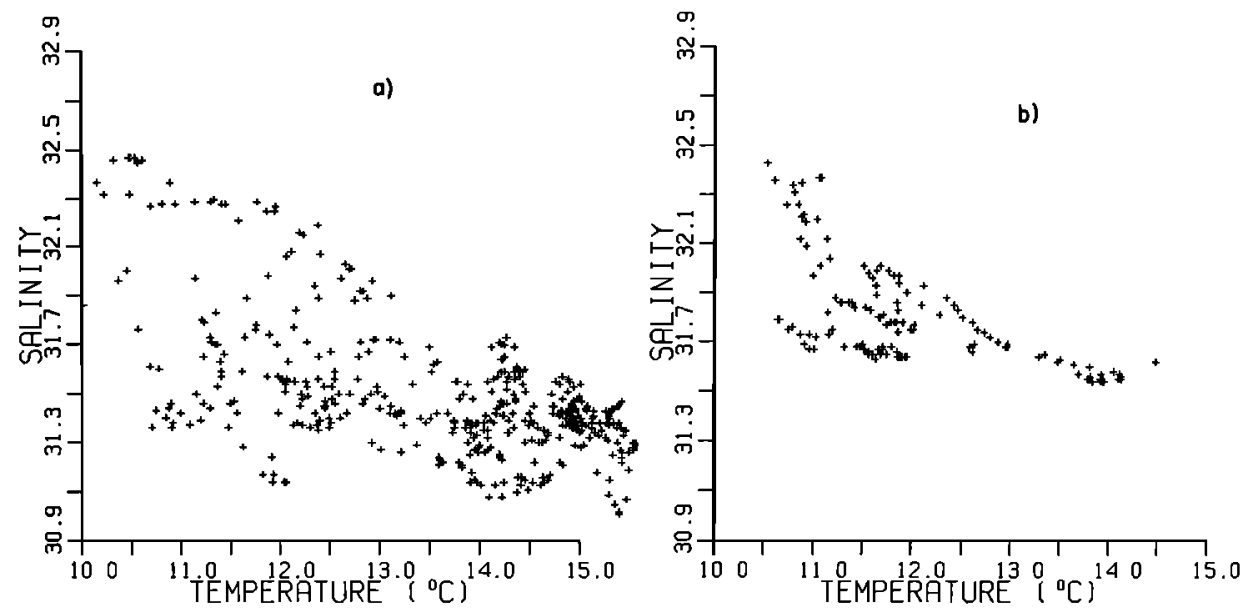

Fig. 6. Summer surface $T-S$ relationships of in situ data from (a) precooling event data (transects $1-4)$ and $(b)$ data during the cooling event (transect 6 ).

changed, temperature and salinity properties of surface water have not. This figure shows that the warm tongue of water visible in Plate $2 b$ has the same $T-S$ characteristics as surface water which previously occupied the entire shell in the northern portion of the study area. This argues that the warm tongue is a residual of the previous stratified conditions.

Summer subsurface isotherms (Figure 7) sloped upward towards the shore. The location of sampling stations is given in Plate $2 a$ in relation to surface thermal patterns. Stratification was weakest in the region of colder surface water (leg 2) centered over Juan de Fuca Canyon, where temperatures in the top $5 \mathrm{~m}$ were below $11.0^{\circ} \mathrm{C}$. A frontal zone separated this vertically mixed water from offshore more stratified water with near-surface temperatures above $13.0^{\circ} \mathrm{C}$. In the northern part of the study area (leg 4), over La Perouse Bank, no frontal zone existed during the initial portion of the sampling period, and stratified, offshore conditions extended across the enture shell.

The summer association of colder surface temperatures with higher salinities is opposite to that found in winter and indi-

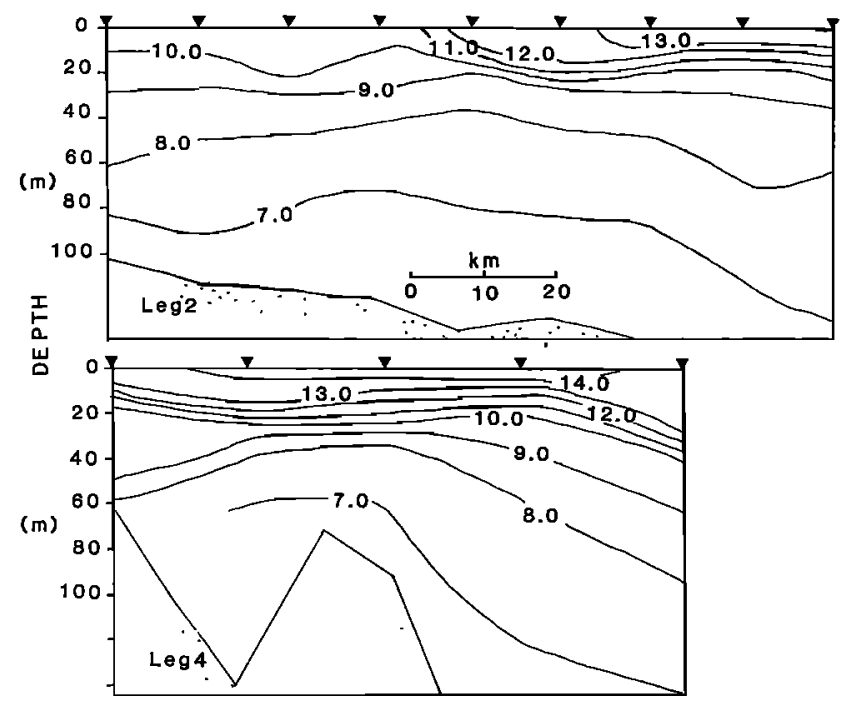

Fig. 7. Cross-shelf contours of summer subsurface temperature from stations through the eddy (leg 2) and north of the eddy (leg 4). Triangles represent station locations, also shown in Plate $2 a$, and depth is in meters. cates a subsurface origin of nearshore colder surface water typical of upwelling systems and characteristic of the Pacific west coast during summer [Pietrafesa, 1983]. The persistent cold feature in the Juan de Fuca Canyon region identified in the image sequence is most likely the surface expression of upwelling induced by the cyclonic eddy described by Freeland and Denman [1982] and analyzed in infrared imagery by Emery et al. [1986].

\section{Plankton Concentrations and SURFACE HYDROGRAPHY}

Thomas and Emery [1986] showed that winter regions of low temperature and salinity were areas of highest chlorophyll and zooplankton concentration. Maximum biomass was in nearshore regions, associated with Vancouver Island Coastal Current water. In southern portions of the study area (legs 1 , 2 , and 3), the frontal zone separating this water from warmer and more saline outer shell water was coincident with localized peaks in both chlorophyll and zooplankton concentration. This peak in concentration, however, did not extend north of the La Perouse Bank area. In warmer water seaward of the frontal zones (Davidson Current and offshore water), zooplankton concentrations were consistently low. Chlorophyll concentrations were lowest in the warmest water over the middle shelf (Davidson Current), and increased again coincident with cooler offshore water over the outer shelf.

Figures $8 a$ and $8 b$ illustrate this quantitative relationship between winter plankton concentrations and the surface hydrographic zones distinguishable on $T-S$ plots. Water from the Davidson Current, Vancouver Island Coastal Current, and offshore zone were each associated with characteristic chlorophyll and zooplankton concentrations. Vancouver Island Coastal Current water and offshore water generally supported chlorophyll concentrations above $0.51 \mathrm{mg} \mathrm{m}^{-3}$. Offshore water was never associated with concentrations below $0.25 \mathrm{mg}$ $\mathrm{m}^{-3}$. Davidson Current water, however, was associated with concentrations below $0.25 \mathrm{mg} \mathrm{m}^{-3}$ and never supported concentrations above $0.51 \mathrm{mg} \mathrm{m}^{-3}$. Zooplankton concentrations above 1900 counts $\mathrm{m}^{-3}$ were associated with Vancouver Island Coastal Current water. Both Davidson Current water and offshore water were characterized by zooplankton concentrations below 1500 counts $\mathrm{m}^{-3}$.

While the hydrographic separation of zooplankton con- 

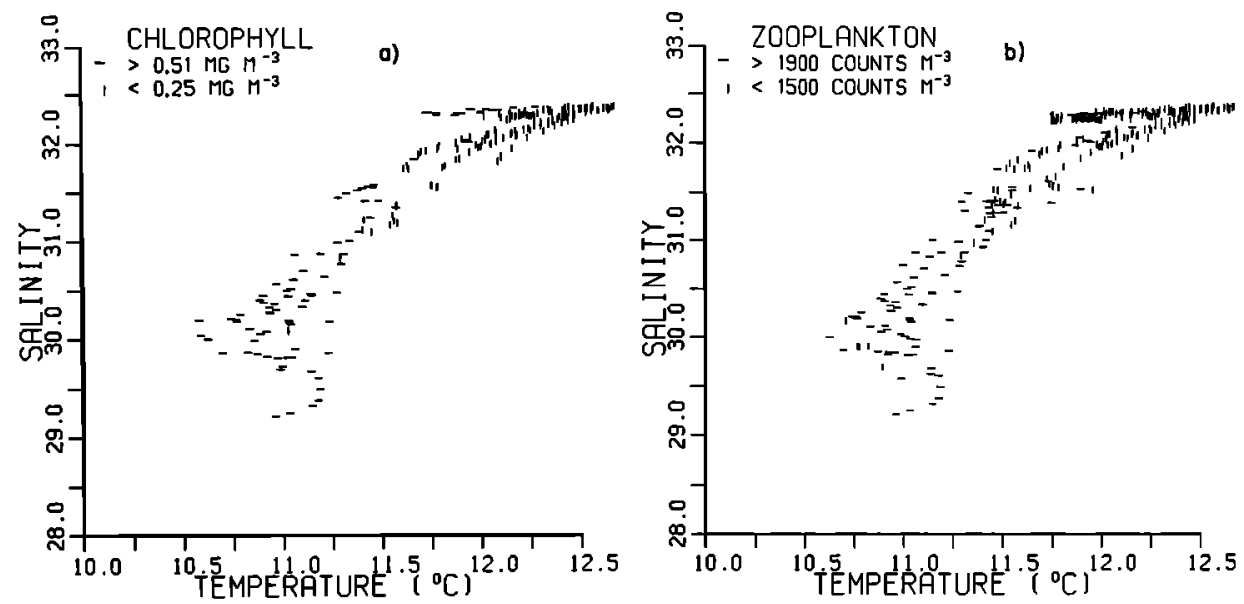

Fig. 8. The association of $(a)$ winter chlorophyll concentrations and $(b)$ winter zooplankton concentrations with surface $T-S$ properties.

centrations in Figure $8 b$ is not as robust as that for chlorophyll concentrations (Figure $8 a$ ), a trend is seen in the sampled points suggesting mixing between Davidson Current water and Vancouver Island Coastal Current water. Values most similar to Davidson Current hydrographic characteristics often had lower chlorophyll and zooplankton concentrations.

Quantitative comparisons of summer plankton con- centrations with surface temperature and salinity characteristics indicated a similar association of specific concentrations with shelf hydrography. Data collected prior to the cooling event, during legs 1-4 (Figures $9 a$ and $9 b$ ) showed that shelf regions with surface temperatures above $13.5^{\circ} \mathrm{C}$ (indicative of the stratified portions of the shelf) never supported chlorophyll concentrations above $5.1 \mathrm{mg} \mathrm{m} \mathrm{m}^{-3}$. This water was generally
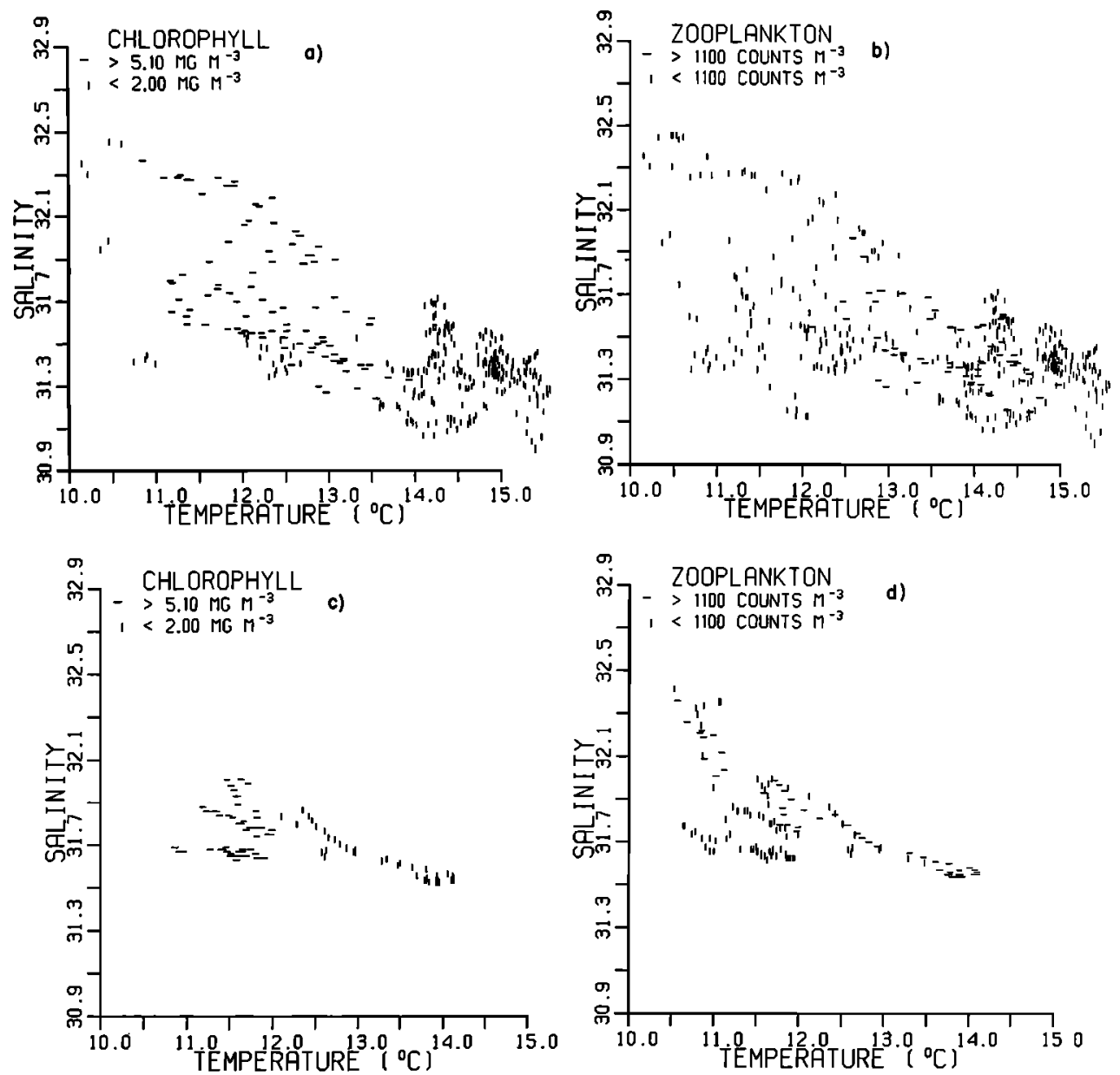

Fig. 9. The association of summer surface plankton concentrations with surface $T$-S properties: (a) chlorophyll and $(b)$ zooplankton concentrations prior to the cooling event (legs 1-4), and (c) chlorophyll and (d) zooplankton concentrations during the cooling event (leg 6). 
associated with concentrations of less than $2.0 \mathrm{mg} \mathrm{m}^{-3}$. In contrast, hydrographic properties indicative of upwelling, with surface temperatures colder than $13.5^{\circ} \mathrm{C}$, rarely had concentrations below $5.1 \mathrm{mg} \mathrm{m}^{-3}$. Exceptions to this pattern occurred at individual sample points with the lowest temperatures $\left(<11.0^{\circ} \mathrm{C}\right)$

Summer zooplankton concentrations prior to the cooling event did not show a consistent association with specific surface hydrographic characteristics (Figure 9b). Concentrations above and below the 1100 counts $\mathrm{m}^{-3}$ threshold occurred in both the warmer and cooler hydrographic regimes. Although highest concentrations ( $>1100$ counts $\mathrm{m}^{-3}$ ) showed a general association with intermediate temperatures, this relationship was not consistent. Numerous sample locations with characteristics in this region of $T-S$ space had lower zooplankton concentrations. Efforts to divide the zooplankton concentrations at different and more numerous thresholds did not simplify their distributional relationship with surface hydrography.

Zooplankton counts measured during the summer were generally lower than those from the winter, a situation inconsistent with normal seasonal trends. Whether this is real or an artifact of sampling is unknown. As mentioned previously, different automated samplers were used for the two sampling periods. Differences in instrument sensitivity, the actual zooplankton size spectrum present, damage to organisms by the two plumbing systems, and zooplankton avoidance would all contribute to the observed difference. As absolute abundances do not affect the results presented here, no effort has been made to cross correlate the two samplers.

Data sampled during the cooling event along leg 6 (Figures $9 c$ and $9 d$ ) indicate that relationships between chlorophyll concentration and hydrography established previously, were maintained despite the dramatic changes in sea surface temperature pattern evident in Plates $2 a$ and $2 b$. Figure $9 c$ shows that chlorophyll concentrations greater than $5.1 \mathrm{mg} \mathrm{m}^{-3}$ were restricted to colder surface water $\left(<12.1^{\circ} \mathrm{C}\right)$. Water warmer than this threshold never supported concentrations greater than $2.0 \mathrm{mg} \mathrm{m}^{-3}$. These data provide biological support for the suggestion based on hydrographic data that this warm tongue was a residual of the warm, stratified water previously occupying this portion of the shelf. Figure $9 d$ again shows an ambiguous association between zooplankton concentrations and hydrography but suggests that the warm water tongue was generally associated with higher concentrations $(>1100$ counts $\mathrm{m}^{-3}$ ).

\section{Plankton Concentrations and Satellite Temperature}

Winter plankton concentration thresholds used to examine relationships between concentration and surface hydrography are superimposed on the mean winter satellite image (Plates $3 a$ and $3 b$ ) to show their spatial relationship with satellitemeasured sea surface temperature patterns. (Plate 3 can be found in the separate color section in this issue.) These data illustrate the association of thermally defined regions with specific plankton concentrations and show that surface thermal fronts visible in the imagery are coincident with boundaries in the plankton regime. Winter chlorophyll concentrations greater than $0.51 \mathrm{mg} \mathrm{m}^{-3}$ are restricted to the cold nearshore zone of the Vancouver Island Coastal Current and the thermal zone seaward of the Davidson Current (offshore water). Increased chlorophyll concentrations are associated with the tongue of coastal current water isolated over the La Perouse Bank area. High concentrations within the coastal current water extend completely into the frontal region in the southern portion of the study area but not at the northern transects on the seaward side of the cold water tongue, indicating a change in biomass associated with the surface frontal zone across the study area. Chlorophyll concentrations of less than $0.25 \mathrm{mg} \mathrm{m}^{-3}$ are primarily restricted to surface water warmer than $12.0^{\circ} \mathrm{C}$. The spatial distribution of this water and its associated chlorophyll concentration in the image show a penetration into the shelf region south of La Perouse Bank and into surface regions on the nearshore side of the bank. Thomas and Emery [1986] discuss the isolation of this water on the shelf in more detail.

Spatial distributions of winter zooplankton concentration in relation to satellite themal patterns (Plate $3 b$ ) reveal the more simplistic division of plankton and hydrographic zones evident in the zooplankton $T-S$-plankton plot. Higher concentrations are generally restricted to the nearshore portion of the shelf, in coastal current water, including high concentrations within the Coastal Current water in the tongue over La Perouse Bank. In warmer water over the middle and outer shelf, winter zooplankton concentrations remained low. Exceptions to this pattern occurred primarily along the northern two transects, where some higher concentrations were seen in Davidson Current water. It is possible that a lack of synopticity contributes to this anomaly. The satellite images making up the mean image were recorded between 24 and 80 hours prior to this in situ sampling of these two transects. The position of the frontal zone and zooplankton concentrations in the in situ data in this region might not be well represented by the mean satellite image.

Summer chlorophyll concentrations superimposed on the mean satellite image (Plate $4 a$ ) show a consistent relationship between their distribution and satellite-measured sea surface temperature. (Plate 4 can be found in the separate color section in this issue.) Plate $4 a$ shows that highest concentrations were associated with cold water, especially around the outer edge of the cyclonic eddy off the mouth of Juan de Fuca Strait. Lowest concentrations were present both in the coldest water in the center of the eddy and also throughout the warmest water. This demonstrates that the relationship shown in the $T$-S-plankton plots was maintained spatially over the entire study area. Chlorophyll concentrations sampled later in the study period along leg 6 (Plate $4 c$ ) showed that despite dramatic changes in the sea surface temperature pattern associated with the cooling event, this relationship between temperature and chlorophyll concentration was maintained. While higher concentrations were present throughout the cooler water now occupying most of the shelf, a decrease in concentration was coincident with the tongue of warm water isolated over the shelf, north of the cyclonic eddy.

Patterns of zooplankton concentration during the early portion of the summer study period (Plate $4 b$ were less consistently related to features visible in the mean image. Increased concentrations in the southern portion of the study area were generally associated with the surface frontal zone at the outer edge of the eddy. Although these increases were not consistent along the frontal region, they do suggest that higher zooplankton biomass was generally coincident with the regions of higher phytoplankton concentration seen in Plate $4 a$. A localized peak in zooplankton concentration was also present along the northern transect in warm, strongly stratified surface 
TABLE 1. Covariance Matrix of Surface Temperature, Chlorophyll, and Zooplankton During the Winter and Summer

\begin{tabular}{|c|c|c|c|c|c|c|c|c|c|}
\hline & \multicolumn{3}{|c|}{ Data } & \multicolumn{3}{|c|}{ Detrended Data } & \multicolumn{3}{|c|}{ Covariance Remaining, \% } \\
\hline & Temperature & Chlorophyll & Zooplankton & Temperature & Chlorophyll & Zooplankton & Temperature & Chlorophyll & Zooplankton \\
\hline \multicolumn{10}{|c|}{ Winter } \\
\hline Temperature & 0.275 & & & 0.155 & & & 56.4 & & \\
\hline Chlorophyll & -0.070 & 0.041 & & -0.054 & 0.039 & & 77.1 & 95.1 & \\
\hline Zooplankton & -228.1 & 83.9 & 429376.5 & -85.3 & 64.7 & 257285.3 & 37.4 & 77.1 & 59.9 \\
\hline \multicolumn{10}{|c|}{ Summer } \\
\hline Temperature & 2.048 & & & 0.429 & & & 20.6 & & \\
\hline Chlorophyll & -2.798 & 15.507 & & -0.375 & 11.543 & & 13.4 & 74.4 & \\
\hline Zooplankton & 53.1 & 271.1 & 1380587.6 & 32.6 & 528.3 & 1227080.5 & 61.4 & 194.9 & 88.9 \\
\hline
\end{tabular}

Values are given for before and after detrending by removal of the least squares fit plane from each of the variables and for the percentage of covariance remaining after detrending.

water. High concentrations in this portion of the study area did not appear to be associated with any identifiable surface hydrographic feature. The highest concentrations seen by Mackas et al. [1980] over the outer shelf in the southern portion of the study area are similar to those seen in Plate $4 b$, although these authors did not observe an associated peak in chlorophyll concentration. The peak in zooplankton concentration evident along the northern transect in the vicinity of La Perouse Bank was also not observed by Mackas et al. [1980]. The image recorded after the cooling event (Plate $4 d$ ) shows that this higher zooplankton concentration was maintained within the warmer water, now isolated as a narrow tongue on the shelf.

\section{Image-Derived Plankton Distributions}

Plates 3 and 4 indicate that relationships between plankton concentrations and surface hydrography not only were maintained when compared with satellite-measured sea surface temperature but also formed coherent and relatively unambiguous spatial patterns similar to those in the satellite imagery. This suggests that major features of the surface distribution of both phytoplankton and zooplankton concentration might be represented by satellite images of surface thermal patterns. Both winter chlorophyll and zooplankton data and summer chlorophyll data collected prior to the cooling event were used to form statistical estimates of the ability of the infrared images to represent plankton distributional patterns. Spatial relationships between summer zooplankton concentrations and the mean image were not consistent enough to allow meaningful statistical estimates of their similarity, and the single transect of both chlorophyll and zooplankton data from the later time period were considered too sparse to attempt a quantitative estimate of similarity.

During both winter and summer, the large-scale structure was a general cross-shelf gradient from colder temperatures and higher plankton concentrations nearer shore to higher temperatures and lower plankton concentrations offshore. The dependence of chlorophyll and zooplankton variance on the large-scale structure was estimated by first examining the covariance matrix of the variables for the entire study area. The dominant trend of each variable was then removed by subtracting a least squares fit plane in $x, y, z$ space, where $z$ was the value of the variable being detrended, and a second covariance matrix calculated from the residuals. Approximately $76 \%$ of the chlorophyll and $37 \%$ of the zooplankton winter covariance with temperature (Table 1) remained after detrending, providing an estimate of the proportions of the winter covari- ance associated with large-scale features and with smallerscale features. The summer covariance matrices (Table 1) show that although $74 \%$ of the chlorophyll variance is associated with small-scale features, only $\approx 13 \%$ of the chlorophylltemperature covariance is associated with features smaller than the length scale of the transects.

Although the larger-scale structure has not been statistically resolved in this study, the cross-shelf gradient making up this structure is a commonly observed feature along the North American west coast [e.g., Mackas et al., 1980; Traganza et al., 1983; Ikeda and Emery, 1984; Abbott and Zion, 1985; Emery $e t$ al., 1986]. Although very few degrees of freedom can be associated with it in this study, it seems reasonable to assume it to be a real and recurring feature.

The small-scale temperature-plankton variability is both more variable in time and space, and less well studied. The high-resolution sampler and the satellite data are especially suited for studying these smaller-scale features. The number of independent realizations associated with the smaller-scale structure can be estimated by calculating a dominant length scale of variability. It can be assumed that on average, data points separated by more than this length scale will be independent, and those closer than this separation are spatially autocorrelated and dependent. Previous authors have used the spatial structure function to investigate length scales in the marine environment [Lutjeharms, 1981; Deschamps et al., 1981 ; Denman and Freeland, 1985]. The spatial structure function,

$$
D^{2}(h)=\frac{1}{n} \sum_{i=1}^{n}\left(f_{(i)}-f_{(i+h)}\right)^{2}
$$

for the variable $f$ at a spatial distance or lag $h$, represents as a mean square difference the statistical influence of a point upon other points at distance $h$. Dominant features of a specific spatial scale will produce a peak in the function at that spatial lag. Scales at which little spatial structure exists will be represented by flat portions of the function [Lutjeharms, 1981].

Structure functions of surface temperature, salinity, chlorophyll, and zooplankton from each leg of each cruise were calculated from the data detrended by a least squares fit straight line to estimate a cross-shelf length scale. Summer chlorophyll and zooplankton data were first $\log _{e}$ transformed as was recommended by Denman and Freeland [1985] to increase the normality of their distributions. This transformation was not applied to the winter biological data because rates of biological processes which tend to cause these variables to depart from a normal distribution, such as grazing and 
growth, are minimal during winter. Structure functions from each cross-shelf transect within a season were averaged to produce a mean function for each variable for the winter and summer sampling periods. The magnitude of the structure function for each variable was then scaled to fit between 0 and 1 , to facilitate comparison.

The structure functions (Figure 10) show that during both winter and summer, a length scale is apparent in the hydrographic and the planktonic data. The winter functions show that chlorophyll and zooplankton reach a distinct peak in dissimilarity at a separation of $\approx 10 \mathrm{~km}$. Both temperature and salinity functions show a change in slope at $\approx 18 \mathrm{~km}$. The summer functions show that chlorophyll, temperature, and salinity reach a broad peak in dissimilarity at $\approx 19 \mathrm{~km}$. The zooplankton structure function shows a much shorter length scale of dissimilarity, suggesting a dissociation from the other variables and shorter length scale patchiness. An alongshore length scale is difficult to calculate from the transects sampled in this study. Denman and Freeland [1985], however, show that temperature, salinity, and chlorophyll all reach a peak of dissimilarity at $\approx 30 \mathrm{~km}$ in this region of the shelf. Mackas [1984] shows that zooplankton biomass has an alongshore length scale of $\approx 25 \mathrm{~km}$. These values suggest that adjacent transects were not independent but that transects separated by more than this distance were.

Using an average cross-shelr length scale for each season and assuming transects separated by more than $30 \mathrm{~km}$ to be independent, the winter data set yields $(461 / 14) / 2 \approx 16.5$ independent realizations and the summer data set yields $(453 / 19) / 2 \approx 12$ independent realizations. These are applicable to that portion of the covariance associated with smaller-scale structure.

The interpretation of the statistics is that while they are an effective representation of the relationship between the satellite data and the plankton concentrations presented here, their statistical applicability outside the time and space scales of the data themselves is unsure.

\section{Winter}

Winter surface chlorophyll and zooplankton concentrations were regressed against mean satellite temperatures using both untransformed and $\log _{e}$ transformed values. The success of these four regressions is presented in Table 2. Biological processes within plankton communities result in an "overdispersed" or patchy distribution of both organisms and other nonconservative properties such as nutrients. Relationships between population variables primarily controlled by these biological processes and any more conservative variable are therefore likely to be most closely described by some form of logarithmic function [e.g., Denman and Freeland, 1985, Abbott and Zion, 1985]. A linear relationship between a relatively conservative tracer of the physical regime (temperature) and a biological variable such as chlorophyll implies that the phytoplankton cells are acting as Lagrangian tracers of the physical regime and their distribution is more likely a result of linear mixing of biomass than active growth.

The error $\varepsilon^{2}$ associated with the winter regression of chlorophyll concentration [chl] and satellite temperature was approximately $22 \%$ less than that associated with the regression of $\log _{e}[\mathrm{chl}]$. This supports the previously presented argument that the biological component of processes controlling distribution are reduced in winter. The magnitude of the errors associated with the regression of $\log _{e}$ [zoop] and [zoop] was
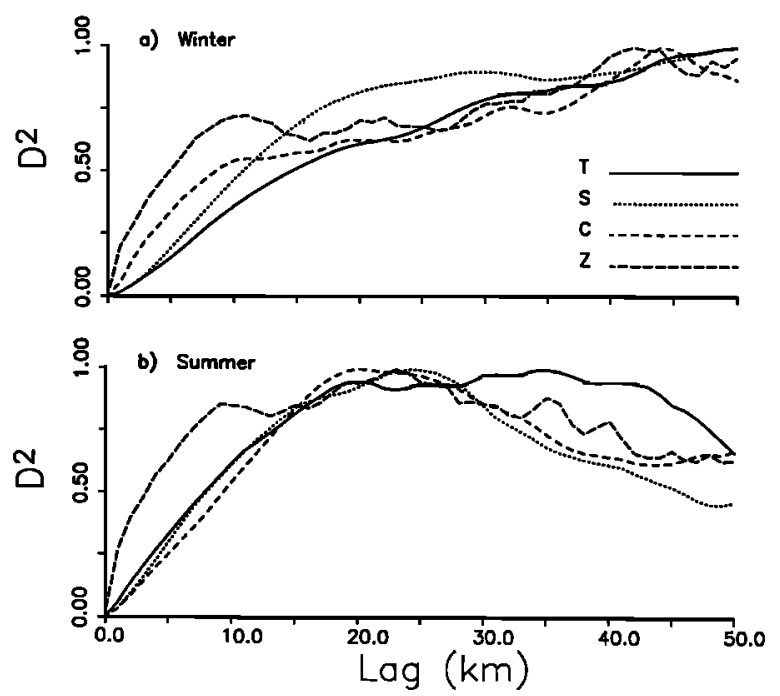

Fig. 10. Mean cross-shelf structure functions of temperature, salintly, chlorophyll concentration, and zooplankton counts for (a) winter and $(b)$ summer, scaled between 0 and 1 . Mean functions for each variable were formed by averaging function values at each lag from the winter and summer transects.

similar. "Plankton" images of [chl] and $\log _{e}$ [zoop] constructed from the regression equations (Plates $5 a$ and $5 b$ ) reproduce the general patterns of distribution indicated by the biomass overlays in Plates $3 a$ and $3 b$, including mesoscale patterns associated with the tongue of coastal water over La Perouse Bank. (Plate 5 can be found in the separate color section in this issue.) These patterns are similar to those shown in the contour plots of Thomas and Emery [1986]. They obviously fail to show smaller-scale peaks in concentration associated with the hydrographic frontal zone in the southern portion of the study area. In this region, peaks in both chlorophyll and zooplankton concentration were more closely associated with surface thermal gradients than surface temperature and will only contribute to the error of a simple regression. The strong surface thermal gradient in the northern portion of the study area (see Plate 1) was not associated with a peak in chlorophyll or zooplankton concentration. This inconsistency prevented a regression of concentration with surface temperature gradient being used to model concentrations along the frontal zone.

Superimposed on each image are the sampled transects, coded to show regions where major departures from the overall regression equation occur (see Plate 5 caption). Consistent patterns in this error indicate regions where failure might be due to systematic changes in the functional relationship between hydrography and plankton concentration. Both images

TABLE 2. Winter Regression Model Statistics for Chlorophyll and Zooplankton Concentration and Mean Satellite Temperature

\begin{tabular}{lccccc}
\hline \multicolumn{1}{c}{ Variable } & $\epsilon^{2}$ & rmsdif & $r^{2}$ & $\alpha$ & $\beta$ \\
\hline [chl] & 0.635 & 0.16 & 0.366 & -0.290 & 3.782 \\
$\log _{e}[\mathrm{chl}]$ & 0.808 & 1.50 & 0.192 & -1.727 & 18.879 \\
{$\left[\mathrm{zoop}^{2}\right.$} & 0.560 & 490.3 & 0.441 & -1028.5 & 13700.2 \\
$\log _{e}[$ zoop] & 0.516 & 0.30 & 0.485 & -0.679 & 15.29 \\
\hline
\end{tabular}

Least squares regression coefficients of the slope and intercept are $\alpha$ and $\beta$; rmsdif is root-mean-square difference in the same units as the variable. $N=461$ for each regression. 
TABLE 3. Winter Density Slice Model Statistics for Chlorophyll and Zooplankton Concentration Using Image-Derived Hydrographic Thresholds

\begin{tabular}{|c|c|c|c|c|c|c|c|}
\hline Variable & Zone & $T$ & $S$ & $\bar{x}$ & rmsdif & $r^{2}$ & $\varepsilon^{2}$ \\
\hline Chlorophyll (Plate 6a) & $\begin{array}{r}\text { total } \\
\text { VICC } \\
\text { DC } \\
\text { offshore } \\
\text { transition }\end{array}$ & $\begin{array}{c}<11.75 \\
>12.06 \\
>12.30 \\
>12.30 \\
11.75-12.06\end{array}$ & $\begin{array}{l}<32.0 \\
=32.25 \\
>32.0 \\
<32.0\end{array}$ & $\begin{array}{l}0.47 \\
\\
0.14 \\
0.46 \\
0.27\end{array}$ & $\begin{array}{l}0.137 \\
0.175 \\
\\
0.119 \\
0.059 \\
0.131\end{array}$ & 0.534 & 0.454 \\
\hline $\begin{array}{l}\text { Chlorophyll (redefined } \\
\text { thresholds; not } \\
\text { shown) }\end{array}$ & $\begin{array}{r}\text { total } \\
\text { VICC } \\
\text { DC } \\
\text { offshore } \\
\text { transition 1 } \\
\text { transition 2 }\end{array}$ & $\begin{array}{l}<11.60 \\
>12.20 \\
>12.30 \\
>12.30 \\
11.60-11.90 \\
11.90-12.20\end{array}$ & $\begin{array}{l}<32.25 \\
=32.25 \\
>32.0 \\
<32.0 \\
<32.0\end{array}$ & $\begin{array}{l}0.48 \\
\\
0.13 \\
0.46 \\
0.20 \\
0.36\end{array}$ & $\begin{array}{l}0.139 \\
0.182 \\
\\
0.113 \\
0.059 \\
0.146 \\
0.139\end{array}$ & 0.526 & 0.471 \\
\hline Zooplankton (Plate 6b) & $\begin{array}{r}\text { total } \\
\text { VICC } \\
\text { transition } \\
\text { offshore }\end{array}$ & $\begin{array}{l}<11.80 \\
>11.80\end{array}$ & $\begin{array}{l}<31.85 \\
>31.85\end{array}$ & $\begin{array}{l}2088.7 \\
1495.3 \\
1070.7\end{array}$ & $\begin{array}{l}481.5 \\
634.6 \\
431.4 \\
333.5\end{array}$ & 0.459 & 0.540 \\
\hline
\end{tabular}

$T$ and $S$ are the mean image temperature and the modeled salinity thresholds used to separate each zone. "Total" refers to all data points in the study area (statistics for the total image), VICC refers to points in the image classified as Vancouver Island Coastal Current water, DC refers to Davidson Current water, and "transition" refers to transition zones between hydrographic regimes. The rms difference rmsdif is in the same units as the original variable, and $\bar{x}$ is the mean concentration within the zone.

show an expected lack of fit in frontal regions, especially in the southern portion of the study area. The chlorophyll image shows that regions occupied by offshore water tend to depart from the overall regression, indicating an inconsistent relationship between temperature and chlorophyll across the shelf. The regression equation is most likely dominated by the gradient from high to low chlorophyll concentrations from colder Vancouver Island Coastal Current water to warmer Davidson Current water. The zooplankton image indicates larger errors at the seaward portions of legs 5 and 6 . It is possible that the previously mentioned lack of synopticity is contributing to the error in these regions. The chlorophyll regression in this region, however, did not seem to be affected.

The $T$-S-plankton plots showed that regions of specific plankton concentration on the winter shelf could be separated in terms of temperature and salinity. A simple mixing model was used to predict surface salinity distribution from the satellite temperature image. Using these two image products, each pixel of the study area could be assigned coordinates in $T-S$ space to mimic the $T-S$-plankton diagrams. Surface water was assumed to be a result of mixing between the three previously described water regimes (Figure 4). Salinity variations within both the Davidson Current and offshore regimes were small, and a mean salinity of 32.35 was calculated from all points within the region. The separation between this region and less saline regimes could be unambiguously identified in the satellite imagery by the distinct surface thermal signature of Davidson Current water. All pixels in the image seaward of the main (warmest) core of this water were assigned this mean salinity.

Salinity variations between this core and coastal current water were modeled as a line of mixing between the warmest Davidson Current water present in the study area $\left(12.65^{\circ} \mathrm{C}\right.$, 32.25 ) and the center of the cluster of points defining coastal current water $\left(10.88^{\circ} \mathrm{C}, 30.00\right)$ (see Figure 4). All pixels shoreward of the main core of Davidson Current water were then assigned the salinity predicted by temperature, assuming mixing along the straight line joining these two water types in $T-S$ space.

The "salinity" image produced from this model showed the same features as contours of measured surface salinity presented by Thomas and Emery [1986]. Redrawn T-S-plankton plots using modeled salinity, mean satellite temperatures, and sampled plankton concentrations showed that this model allowed the same separation of water types and plankton concentrations as that seen in the original $T-S$-plankton plots (Figures $8 a$ and $8 b$ ).

Hydrographic thresholds used to define regions of similar plankton concentration in satellite derived $T-S$ space are given in Table 3 along with mean concentrations calculated for the resultant regions. "Plankton" images constructed from these means are given in Plates $6 a$ and $6 b$. (Plate 6 can be found in the separate color section in this issue.) Statistics of these images (Table 3) show that Plate $6 a$ reduced the error of the chlorophyll estimation to 0.454 , considerably less than the simple temperature regression model. This model explained approximately $55 \%$ of the sampled chlorophyll variance with an overall $\mathrm{rms}$ difference of $0.137 \mathrm{mg} \mathrm{m}^{-3}$. The majority of the unexplained variance was associated with colder coastal current water. Chlorophyll concentrations in both Davidson Current and offshore water were more effectively modeled with rms differences of 0.119 and $0.059 \mathrm{mg} \mathrm{m}^{-3}$, respectively. The error associated with the zooplankton image (Plate $6 b$ ) was higher than the error associated with the $\log _{e}$ regression model. Table 3 shows that the offshore water had the lowest rms difference, indicating that concentrations within this hydrographic regime were the most precisely modeled. Zooplankton concentrations in coastal current water had the greatest rms difference and were the least precisely modeled.

The transects overlayed on these "plankton" images give a spatial representation of the model errors. Consistent errors at the boundaries of hydrographic zones are indicative of slight mismatches in synopticity. While the mean image provides the best reduction of the satellite image series to represent surface 
thermal patterns over the study period, it obviously loses the more precise coregistering of individual in situ transects with concurrent satellite imagery. Errors in both the chlorophyll and zooplankton models within the coastal current regime reflect the inability of this simple modeling approach to reproduce the increased spatial patchiness of this zone. The remarkably effective representation of surface plankton concentrations within the Davidson Current and offshore zones indicates a strong dominance of plankton distributional patterns by large-length-scale physical mixing processes.

A further effort was made to reduce the error of the threshold chlorophyll model by subdividing the image into another $T-S$ region, and narrowing the threshold limits of previously defined hydrographic regions. Redefined thresholds for these five regions are given in Table 3 . No attempt was made to improve the extremely low rms difference in offshore water. Statistics of this model (Table 3) show a slight improvement in the modeling of Davidson Current water concentrations, but both coastal current and unlabeled mixed water retain similar rms differences. The image overall had a slightly greater rms difference $\left(0.139 \mathrm{mg} \mathrm{m}^{-3}\right)$ than that of the four-zone model (Plate $6 a$ ), indicating a limit to the amount of plankton variance directly associated with $T-S$ properties.

\section{Summer}

Summer $T$-S-plankton plots (Figure 9a) showed that (unlike in winter) the majority of chlorophyll variation was associated with temperature and that salinity need not be considered. These figures also show no consistent relationship between zooplankton concentration and surface hydrography. Attempts to derive quantitative models of surface zooplankton distribution from surface temperature were not successful.

Regressions of chlorophyll concentration on mean satellite temperature (Table 4) showed that $\log _{e}$ transformed concentrations produced $40 \%$ less error than untransformed concentrations and explained approximately $60 \%$ of the sampled variance. The "plankton" image produced by the $\log _{e}[\mathrm{chl}]$ regression equation is shown in Plate 7. (Plate 7 can be found in the separate color section in this issue.) The increased success of the $\log _{e}$ transformed regression is indicative of a significant biological control of patterns of chlorophyll concentration over the summer shelf. It implies a linear mixing of exponentially changing population variables such as growth rate rather than a simple linear mixing of biomass as was observed in winter. Plate 7 shows the location of highest chlorophyll concentrations in zones of colder water within the upwelling regions and lower concentrations within zones of warmer, vertically stratified water. Departures from the overall regression were maximum in the colder zone, especially around its outer edge, where maximum biomass was observed.

TABLE 4. Summer Regression Model Statistics for Chlorophyll and Zooplankton Concentration and Satellite Temperature (Legs 1 - 4)

\begin{tabular}{|c|c|c|c|c|c|}
\hline Variable & rmsdif & $r^{2}$ & $\epsilon^{2}$ & $\alpha$ & $\beta$ \\
\hline [chl] & 3.238 & 0.324 & 0.676 & -2.587 & 37.965 \\
\hline $\log _{e}[\mathrm{chl}]$ & 0.747 & 0.607 & 0.392 & -1.070 & 14.883 \\
\hline [zoop] & 1174.8 & 0.0003 & 0.9997 & 23.2 & 335.3 \\
\hline $\log _{e}[\mathrm{zoop}]$ & 0.994 & 0.022 & 0.978 & -0.231 & 8.764 \\
\hline
\end{tabular}

Least squares regression coefficients for slope and intercept are given as $\alpha$ and $\beta$; rmsdif is in the same units as the variable $(N=$ 453).
TABLE 5. Summer Density Slice Model Statistics for Chlorophyll Concentration Using Temperature Thresholds

\begin{tabular}{llcccc}
\hline Zone & \multicolumn{1}{c}{$T$} & $\bar{x}$ & rmsdif & $r^{2}$ & $\varepsilon^{2}$ \\
\hline Total & & & 3.112 & 0.391 & 0.625 \\
Stratified & $>13.8$ & 0.57 & 0.689 & & \\
Coldest & $<12.0$ & 2.24 & 0.594 & & \\
Frontal & $12.0-13.8$ & 5.53 & 4.470 & & \\
\hline
\end{tabular}

$T$ is temperature from the mean satellite image. "Total" refers to all sampled data points, "stratified" refers to offshore warmest water, "coldest" refers to most recently upwelled water, and "frontal" refers to upwelled water of intermediate temperature around the edge of the upwelling zone.

The lack of correlation between zooplankton concentration and satellite temperature is evident in Table 4.

A significant failure of the regression equation was the prediction of highest chlorophyll concentrations in the coldest and most recently upwelled water in the center of the eddy. This does not follow the established association of chlorophyll and surface temperature in an upwelling region. Lower concentrations are expected in most recently upwelled water, with maximum values at some intermediate temperature on the outer edge of the upwelling zone in "older" upwelled water [e.g., MacIsaac et al., 1985].

Temperature thresholds which would partition the shelf into three zones of chlorophyll concentration representing warm regions (stratified water) with low concentrations, cold regions (most recently upwelled water) also with low concentrations, and intermediate temperatures (older upwelled water) with highest concentrations were identified from the $T$-S-plankton plot. The mean summer image was then sliced at these thresholds, and a "plankton" image was created by assigning the mean chlorophyll concentrations (calculated from in situ data) to each zone. These temperature thresholds, the mean chlorophyll concentrations, and the rms differences for each region (Table 5) show that the warm stratified region and the newly upwelled, coldest water were most effectively modeled. The greatest error was, not surprisingly, associated with the frontal zone around the outer edge of the eddy where the highest concentrations were observed. Although the density slice model reproduced the three major regions of chlorophyll concentration expected from theoretical considerations, the total error associated with the resultant "plankton" image was larger than that of the regression model (Table 4), explaining only $\approx \mathbf{4 0} \%$ of the sampled variance.

The association of lower chlorophyll concentrations with both the coldest water and the warmest water and the association of maximum concentrations with an intermediate temperature suggested that the data might best be modeled by a nonlinear equation. A Gaussian equation would reproduce this relationship, predicting decreasing concentrations with both increasing and decreasing temperatures away from a chlorophyll maximum. A Gaussian curve of the form

$$
\log _{e}[\mathrm{chl}]=a \exp \left[-b(T-c)^{2}\right]+d
$$

where $T$ is the satellite temperature in degrees celsius was fitted to the data using a least squares approximation. These data and the resultant curve are shown in Figure 11. The least squares approximation of the regression coefficients was

$$
a=3.5645 \quad b=0.3379 \quad c=12.5992 \quad d=-1.8949
$$




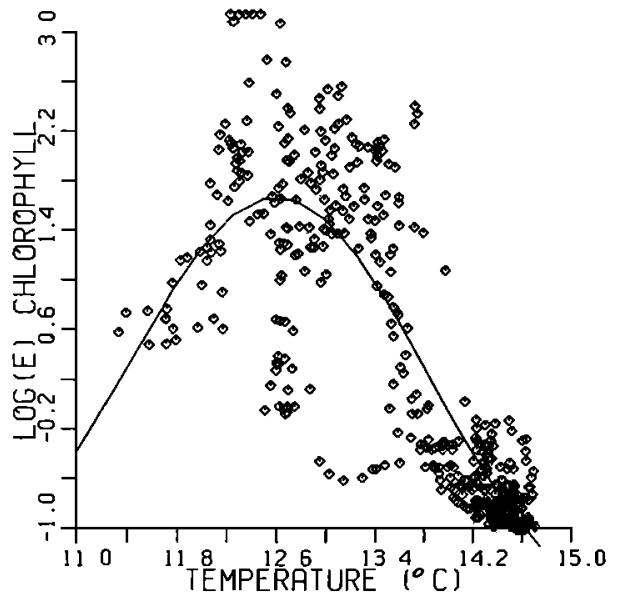

Fig. 11. Relationship between $\log _{e}$ transformed summer chlorophyll concentrations and satellite temperatures, showing the least squares fit nonlinear equation.

with $c$ representing the temperature at which maximum chlorophyll concentrations were present. The "plankton" image created from this regression equation is shown in Plate 8 , and the statistics of its relationship with sampled data are given in Table 6 . This model reduced the $\log _{e} \mathrm{rms}$ difference between actual and modeled data to $0.628 \mathrm{mg} \mathrm{m}^{-3}$ and explained approximately $72 \%$ of the sampled chlorophyll variance. The error associated with this model is approximately $30 \%$ less than that of the linear regression.

Plate 8 shows a circular zone of maximum chlorophyll concentration around the edge of the cold upwelling region (see Plate 2a). (Plate 8 can be found in the separate color section in this issue.) Lower concentrations are in the center of this region. A relatively sharp gradient coinciding with the thermal front (Plate $2 a$ ) separates the zone of high concentrations from low concentrations found in warmer, stratified water outside the upwelling region over the rest of the shelf and shelf break.

The spatial pattern of error associated with this model reflects primarily the increased variance within the region of maximum biomass (Plate $4 a$ ). A region of increased error along the southern transects is coincident with the transition from maximum biomass to minimum biomass at the thermal frontal zone. In this region, slight differences in synopticity contribute to the error. At frontal zones, minimal spatial and/or temporal changes in the thermal gradient position or magnitude would create maximum departures from the regression equation. A comparison with Plate $4 b$ shows that this region is also a zone of maximum zooplankton concentration. Increased grazing rates along this portion of this transect probably also contribute to the observed departures from the overall regression equation.

The spatial relationship between summer temperature and chlorophyll measured in this study resembles that reported by Abbott and Zion [1985] for data from an upwelling region off California. These authors reported similar correlation coefficients for linear regressions relating satellite-measured $\log _{e}$ chlorophyll concentrations to satellite temperature and showed that a nonlinear model improves the predictive capability of the regression (they do not give the mathematical form of their equation). Although higher concentrations are expected to coincide with cooler surface temperatures in upwelling systems, maximum concentrations occur downstream of the most recently upwelled water [e.g., Jones et al., 1983;
Brink et al., 1981] Upwelling reported by these authors was induced by episodic wind events. Data reported here indicate that similar spatial relationships between surface chlorophyll concentration and surface temperature occur in the topographically induced upwelling zone on the southern British Columbia coast.

Summer chlorophyll distributions shown in Plate 8 differ from those reported by Mackas et al. [1980] and Denman et al. [1981]. These authors showed high concentrations over the outer edge of La Perouse bank, immediately seaward of a region of mixing over the shallow banks. Plates $4 a$ and 8 show that this region has low chlorophyll concentrations, and Figure 7 shows it to be stratified. In addition, neither surface temperature nor chlorophyll distributions shown by these authors indicated the presence of an upwelling eddy. Highest surface salinities shown by Mackas et al. [1980] were associated with offshore zones of maximum temperature. This is not indicative of active upwelling. Physical processes during these studies seem to be quite different from those reported here and are probably largely responsible for the observed differences in plankton distribution. These differences emphasize the variable nature of the oceanography in this region of the shelf and highlight the importance of frequent and synoptic sampling by remote sensing techniques.

\section{SUMmARY}

Both winter and summer surface hydrographic zones on the southern British Columbia continental shelf were associated with specific plankton concentrations. Comparisons of these plankton concentrations with surface temperatures mapped by infrared satellite images showed that associations demonstrated in $T-S$ space were coherent in space over the study area. These associations, as well as least squares regression equations, were used to build satellite image derived models of surface plankton distribution. The similarity of winter plankton and hydrographic distributions as well as the general positive correlation of phytoplankton and zooplankton concentrations indicate either a large degree of physical control over biological distributions or a rapid biological response to physical forcing. During winter, low incident light and lowtemperature regimes in temperate latitudes will slow biological processes, reducing the biological component of any response. Winter plankton will act more as Lagrangian tracers of the physical regime. This implies that the similarity in distributions of hydrographic and biological variables on the winter shelf was primarily a function of physical advective processes. Distributions of summer plankton concentrations indicated an interaction between physical processes and biological response. A nonlinear regression equation relating summer surface chlorophyll concentrations and temperature showed a frontal zone of maximum biomass associated with the thermal

TABLE 6. Summer Nonlinear Regression Model Statistics for $\log _{e}$ Chlorophyll Concentration and Satellite Temperature (Legs 1-4)

\begin{tabular}{ll}
\hline & Value \\
\hline Variable & $\log _{e}[\mathrm{chl}]$ \\
rmsdif & 0.628 \\
$r^{2}$ & 0.719 \\
$\varepsilon^{2}$ & 0.277 \\
\hline
\end{tabular}

Regression coefficients and the form of the nonlinear equation are given in the text $(N=453)$. 
frontal zone separating the upwelling area from stratified regions of the shelf. In contrast to the relatively good relationship between surface temperature and winter zooplankton and with both winter and summer chlorophyll, no consistent quantitative relationship existed between summer zooplankton concentrations and satellite temperature. Qualitative associations, however, suggested that maximum biomass was located around the outer edge of an upwelling area, in regions of higher chlorophyll concentration.

Data presented here illustrate that the ability of infrared satellite images to monitor physical processes has important implications for the monitoring and mapping of resultant biological distributions. These plankton distributions have both a physical (mixing and advective) component and a biological (nutrient uptake, cell division, and grazing) component. In situations where the biological component is either reduced or strongly correlated with the physical component, the relationship between concentration and surface temperature can often be exploited, allowing satellite images of sea surface temperature to reproduce the general spatial characteristics of surface plankton distributions. Statistical relationships between these spatial distributions, measured and quantified here for the southern British Columbia continental shelf, demonstrate both an interpolatory and a predictive role for infrared imagery when used in conjunction with concurrent in situ sampling.

Acknowledgments. We are grateful to D. L. Mackas, M. R. Abbott, G. A. Borstad, and T. R. Parsons for useful discussions and comments on various aspects of the work presented here. Bill Meyers, Denis LaPlante, and Paul Nowlan provided technical assistance with the Image processing and Broccoli Oceanographic Inc. of Sidney, British Columbia, provided support at sea. This work was supported by the Canadian Natural Sciences and Engineering Council and the Science Council of British Columbia for collaborative work between the authors and G. A. Borstad Lid. of Sidney on biological applications of infrared imagery. Support during the preparation of this manuscript for one of the authors (A.C.T.) was by NASA grant NAGW-1251.

\section{REFERENCES}

Abbott, M. R., and P. M. Zion, Satellite observations of phytoplankton variability during an upwelling event, Cont. Shelf Res., 4, 661$680,1985$.

Boyd, S. H., P H Wiebe, R. H. Backus, J. E. Craddock, and M. A. Daher, Biomass in the micronekton in Gulf Stream ring 82-B and environs: Changes with Lime, Deep Sea Res., 33, 1885-1905, 1986.

Breaker, L. C., The application of satellite remote sensing to west coast fisheries, Mar. Technol. Soc. J., 15, 32-40, 1981.

Brink, K. H., B. H. Jones, J. C. Van Leer, C. N. K. Mooers, D. W. Stuart, M. R. Stevenson, R. C. Dugdale, and G. W. Heburn, Physical and biological structure and variability in an upwelling center off Peru near $15^{\circ} \mathrm{S}$ during March 1977, in Coastal Upwelling. Coastal and Estuarine Sci., vol. 1, edited by F. A. Richards, pp. 473-495, AGU, Washington, D. C., 1981.

Campbell, J. W., and W. E. Esaias, Spatial patterns in temperature and chlorophyll on Nantucket Shoals from airborne remote sensing data, May 7-9, 1981, J. Mar. Res., 43, 139-161, 1985.

Denman, K. L., Covariability of chlorophyll and temperature in the sea, Deep Sea Res., 23, 539-550, 1976.

Denman, K. L., and H. J. Freeland, Correlation scales, objective mapping, and a statistical test of geostrophy over the continental shelf, J. Mar, Res., 43, 517-539, 1985.

Denman, K. L., and T. Platt, Coherences in the horizontal distribution of phytoplankton and temperature in the upper ocean, Mem. Soc. R. Sci. Liege, 7, 19-30, 1975.

Denman, K. L., and T. M. Powell, Effects of physical processes on planktonic ecosystems in the coastal ocean, Oceanogr. Mar. Biol., $22,125-168,1984$.

Denman, K. L., D. L. Mackas, H. J. Freeland, M. J. Austin, and S. H. Hill, Persistent upwelling and mesoscale zones of high productivity off the west coast of Vancouver Island, Canada, in Coastal Upwell- ing, Coastal and Estuarine Sci., vol. 1, edited by F. A. Richards, pp. 514-521, AGU, Washington, D. C., 1981.

Deschamps, P. Y., R. Frouin, and L. Wald, Satellite determination of the mesoscale variability of the sea surface temperature, $J$. Phys. Oceanogr., 11, 961-970, 1981.

Emery, W. J., and M. Ikeda, A comparison of geometric correction methods for AVHRR imagery, Can. J. Remote Sens., 10, 46-56, 1983.

Emery, W. J., A. C. Thomas, M. J. Collins, W. R. Crawford, and D. L. Mackas, An objective method for computing advective surface velocities from sequential infrared satellite images, J. Geophys. Res., 91, 12,865-12,878, 1986.

Eppley, R. W., Temperature and phytoplankton growth in the sea, Fish. Bull., 90, 1063-1085, 1972.

Fasham, M. J. R., and P. R. Pugh, Observations on the horizontal coherence of chlorophyll and temperature, Deep Sea Res., 23, 527$538,1976$.

Fournier, R. O., M. Van Det, J. S. Wilson, and N. B. Hargreaves, Influence of the shelf break front off Nova Scotia on phytoplankton standing stock in winter, J. Fish. Res. Board Can., 36, 1228-1237, 1979.

Freeland, H. J., and K. L. Denman, A topographically controlled upwelling center off southern Vancouver Island, J. Mar. Res., 40, 1069-1093, 1982.

Freeland, H. J., W. R. Crawford, and R. E. Thomson, Currents along the Pacific coast of Canada, Atmos. Ocean, 22, 151-172, 1984.

Haury, L. R., J. J. Simpson, J. Peláez, C. J. Koblinsky, and D. Wiesenhahn, Biological consequences of a recurrent eddy off Point Conception, California, J. Geophys. Res., 91, 12,937-12,956, 1986.

Ikeda, M., and W. J. Emery, A continental shelf upwelling event off Vancouver Island as revealed by satellite infrared imagery, J. Mar. Res., 42, 303-317, 1984.

Ikeda, M., W J. Emery, and L. A. Mysak, Seasonal variability in meanders of the California Current System off Vancouver Island, $J$. Geophys. Res., 89, 3487-3505, 1984.

Jones, B. H., K. H. Brink, R. C. Dugdale, D. W. Stuart, J. C. Van Leer, D. Blasco, and J. C. Kelley, Observations of a persistent upwelling center of Point Conception, Californı, in Coastal Upwelling: Its Sediment Record, edited by E. Suess and J. Thiede, pp. 37-60. Plenum, New York, 1983.

Lasker, R., J. Peláez, and R. M. Laurs, The use of satellite infrared imagery for describing ocean processes in relation to spawning of the northern anchovy, Remote Sens. Environ., 11, 439-453, 1981

Laurs, R. M., P. C. Fiedler, and D. R. Montgomery, Albacore tuna catch distributions relative to environmental features observed from satellites, Deep Sea Res., 3I, 1085-1099, 1984.

Legendre, L., and S. Demers, Towards dynamic biological oceanography and lımnology, Can. J. Fish, Aquat. Sci., 41, 2-19, 1984.

Lekan J. F., and R. E. Wilson, Spatial variability of phytoplankton biomass in the surface waters of Long Island, Estuarine Coastal Shelf Sci., 6, 239-251, 1978.

Lutjeharms, J. R., Spatral scales and intensities of circulation in the ocean areas adjacent to South Africa, Deep Sea Res., 28, 1289-1302, 1981

MacIsaac, J. J., R. C. Dugdale, R. T. Barber, D. Blasco, and T. T. Packard, Primary production cycle in an upwellıng center, Deep Sea Res., 32, 503-529, 1985.

Mackas, D. L., Spatial autocorrelation of plankton community composition in a continental shell ecosystem, Limnol. Oceanogr., 29, 451-471, 1984.

Mackas, D. L., G. C. Louttit, and M. J. Austin, Spatial distribution of zooplankton and phytoplankton in British Columbia coastal waters, Can. J. Fish. Aquat. Sci., 37, 1476-1487, 1980.

Mackas, D. L., K. L. Denman, and M. R. Abbott, Plankton patchiness: Biology in the physical vernacular, Bull. of Mar. Sci., 37, 652-674, 1985

McClain, E. P., Splıt window and trıple window sea surface temperature determination from satellite measurements, paper presented at Mini-Symposium on Application of Aerospace Remote Sensing in Marine Research, ICES Statutory Meeting, Int. Counc. for the Explor. of the Sea, 1981.

Millard, S. P., J. R. Yearsley, and D. P. Lettenmaier, Space-time correlation and its effects on methods for detecting aquatic ecological change, Can. J. Fish. Aquat. Sci., 42, 1391-1400, 1985.

Pietrafesa, L. J., Shellbreak circulation, fronts and physical oceanography: East and west coast perspectives, Spec. Publ. Soc. Econ. Paleontol. and Mineral., 33, 233-250, 1983. 
Simpson, J. J., C. J. Koblinsky, J. Peláez, L. R. Haury, and D. Wiesenhahn, Temperature-plant pigment-optical relations in a recurrent offshore mesoscale eddy near Point Conception, California, J. Geophys. Res., 91, 12,919-12,936, 1986.

Smith, S. L., and J. J. Vidal, Spatial and temporal effects of salinity, temperature and chlorophyll on the communities of zooplankton in the southeastern Bering Sea, J. Mar. Res., 42, 221-257, 1984.

Steele, J. H., and E. W. Henderson, Spatial patterns in North Sea plankton, Deep Sea Res., 26, 955-963, 1979.

Thomas, A. C., and W. J. Emery, Winter hydrography and plankton distributions on the southern British Columbia shelf, Can. J. Fish. Aquat. Sci., 43, 1249-1258, 1986.

Thomson, R. E., and J. F. R. Gower, A wind-induced mesoscale eddy over the Vancouver Island continental slope, J. Geophys. Res., 90, 8981-8993, 1985.

Traganza, E. D., V. M. Silva, D. M. Austin, W. L. Hanson, and S. H. Bronsınk, Nutrient mapping and recurrence of coastal upwelling centers by satellite remote sensing: Its implication to primary production and the sediment record, in Coastal Upwelling: Its Sediment Record, edited by E. Suess and J. Thiede, pp. 61-83, Plenum, New York, 1983.

Wiebe, P. H., G. R. Flierl, C. S. Davis, V. Barber, and S. H. Boyd, Macrozooplankton biomass in Gulf Stream warm core rings: Spatıal distrıbution and temporal changes, J. Geophys. Res., 90, 8885$8901,1985$.

W. J. Emery, Colorado Center for Atmospheric Research, University of Colorado, Boulder, CO 80309.

A. C. Thomas, College of Oceanography, Oceanography Administration Building 104, Oregon State University, Corvallis, OR 97331.

(Received June 30, 1988; revised July 19,1988 ; accepted July 22, 1988 . 


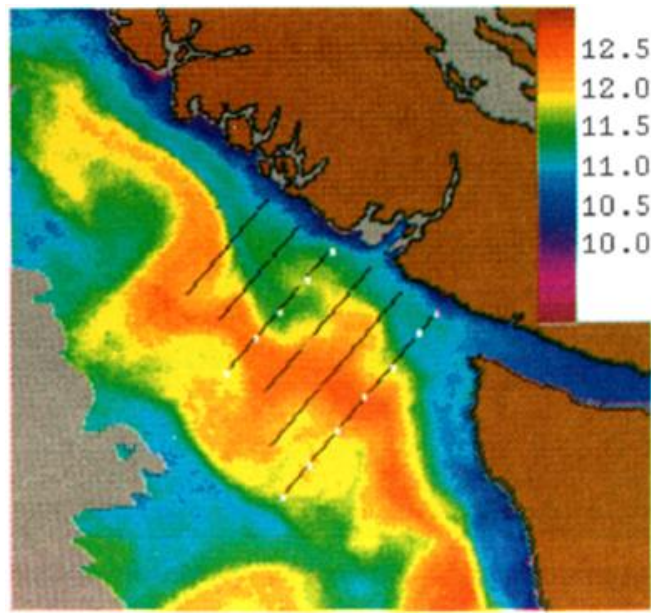

Plate 1 [Thomas and Emery]. Winter mean SST ımage showing the major surface thermal zones, in situ sampling transects, and positions of vertical sampling stations. The image is a mean of the nine most cloud-free images.

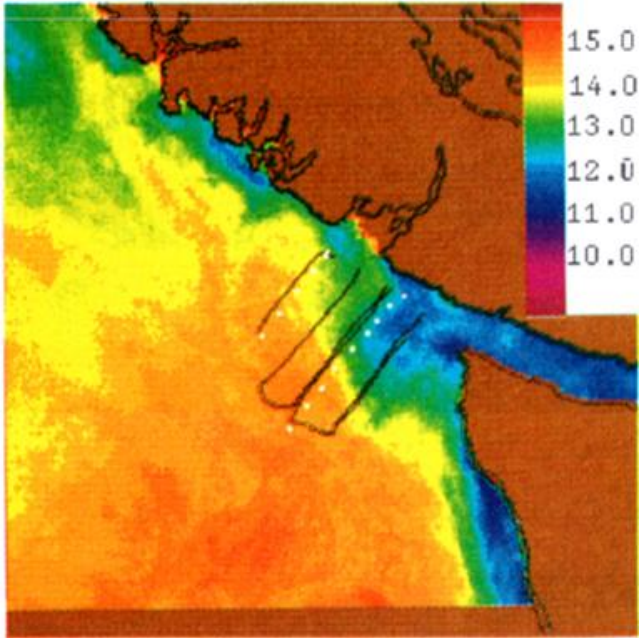

Plate $2 a$

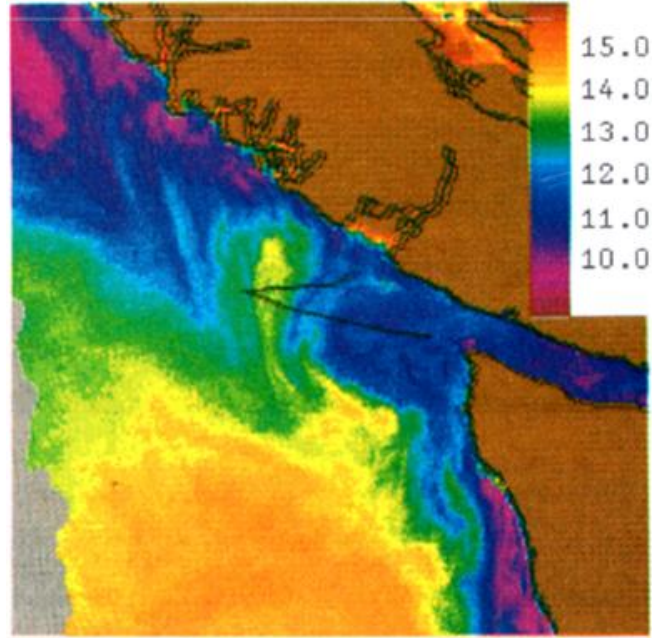

Plate $2 b$

Plate 2 [Thomas and Emery]. (a) Summer mean SST image, representing the nine highly correlated images recorded prior to the cooling event and (b) single image (NOAA 6, July 17) representing thermal patterns sampled in leg 6 during the cooling event. Superimposed are in situ sampling transects (black) and, in Plate $2 a$, positions of vertical sampling stations (white).

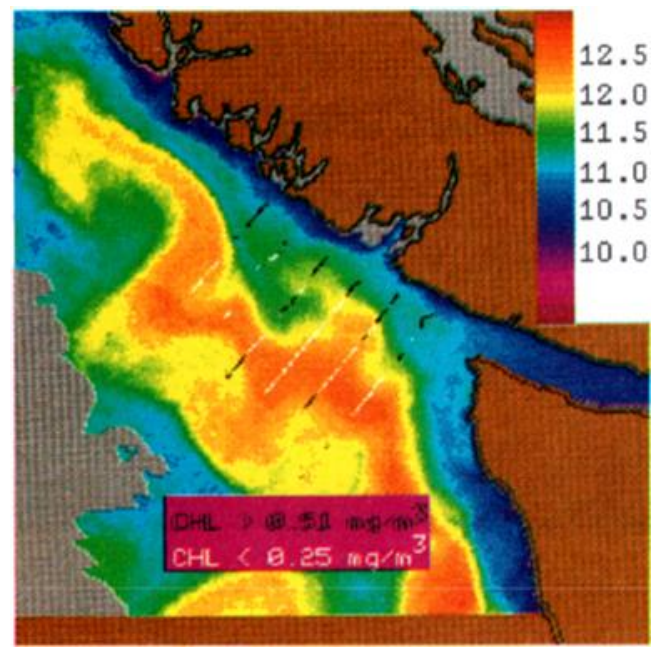

Plate $3 a$

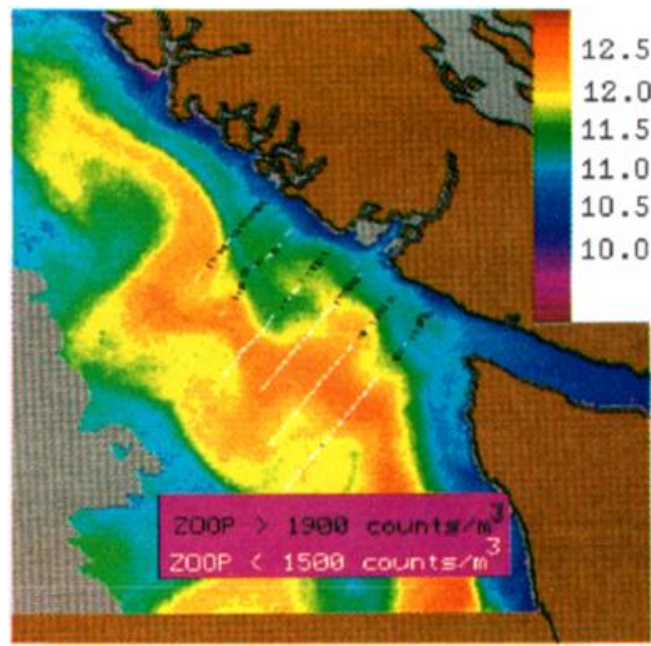

Plate $3 b$

Plate 3 [Thomas and Emery]. Winter mean SST image showing relationships between thermal patterns and plankton concentrations. Thresholds of $(a)$ surface chlorophyll concentration and $(b)$ surface zooplankton concentration are shown along each transect. 


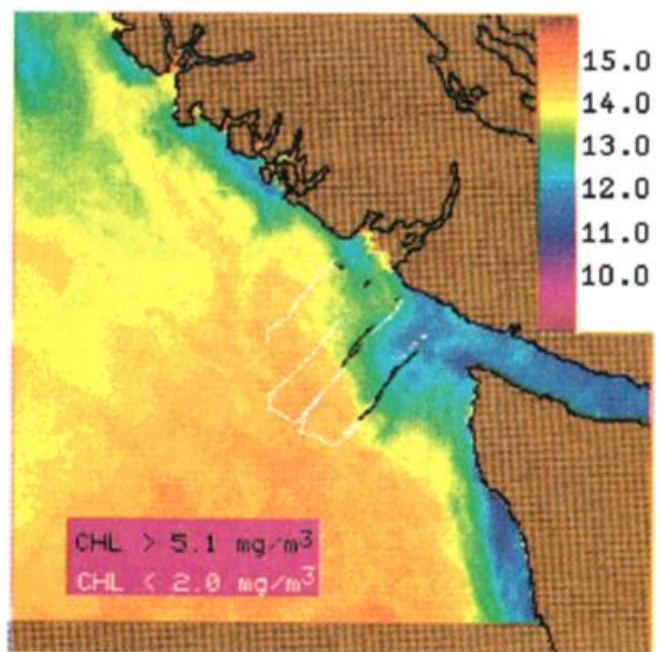

Plate $4 a$

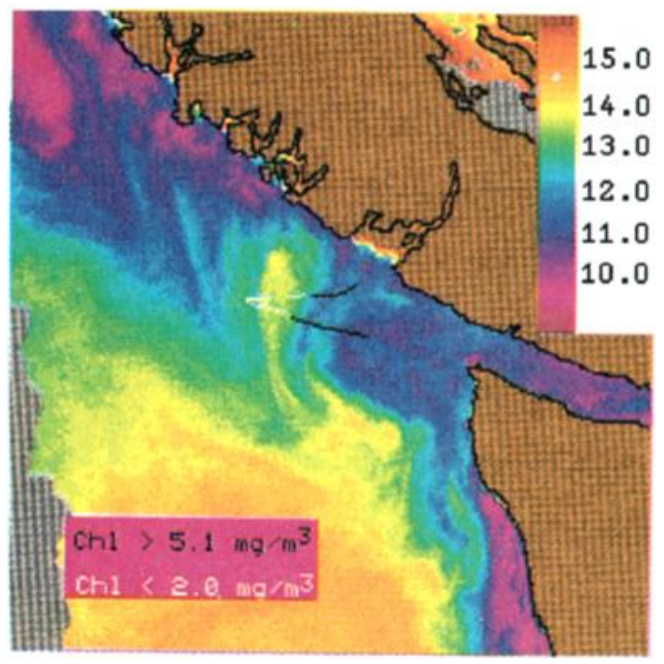

Plate $4 c$

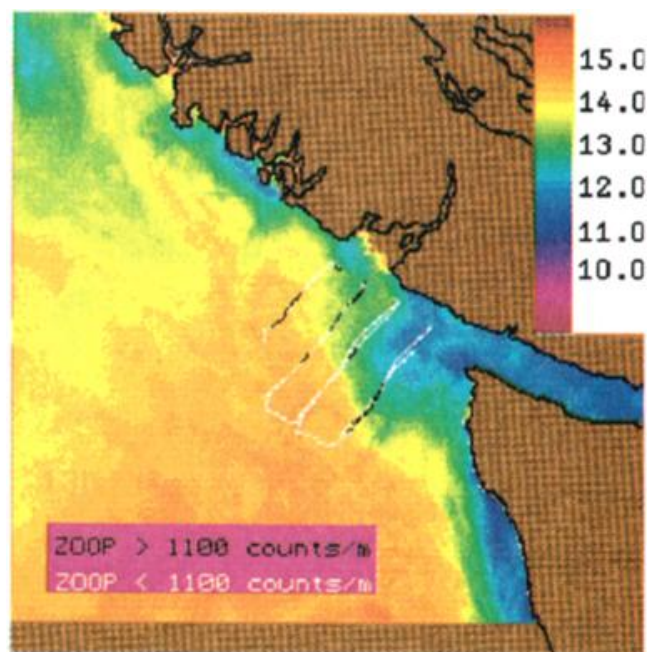

Plate $4 b$

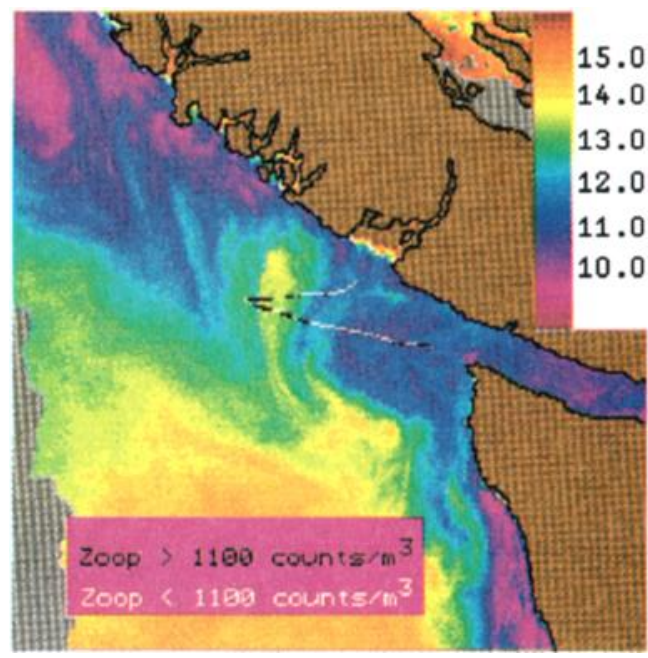

Plate $4 d$

Plate 4 [Thomas and Emery]. Summer SST images showing thresholds of $(a)$ surface chlorophyll and $(b)$ zooplankton concentrations along each transect prior to the cooling event in relation to thermal patterns, and $(c)$ chlorophyll and $(d)$ zooplankton concentrations from leg 6 in relation to thermal patterns on July 16.

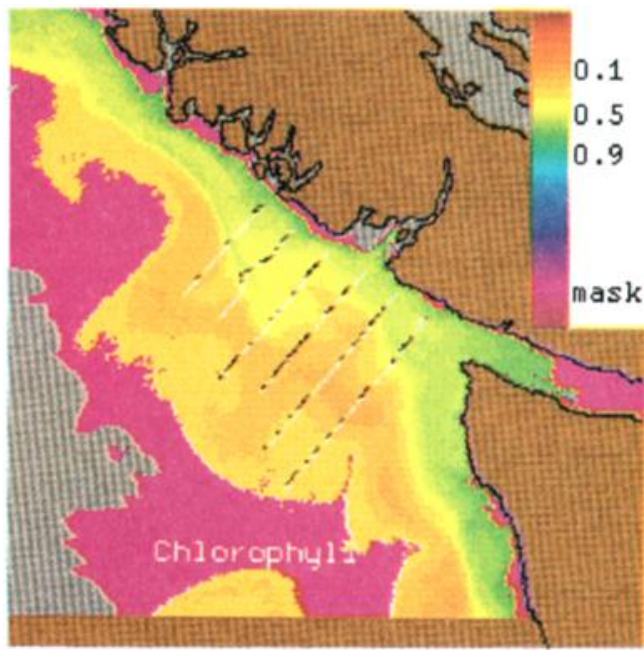

Plate $5 a$

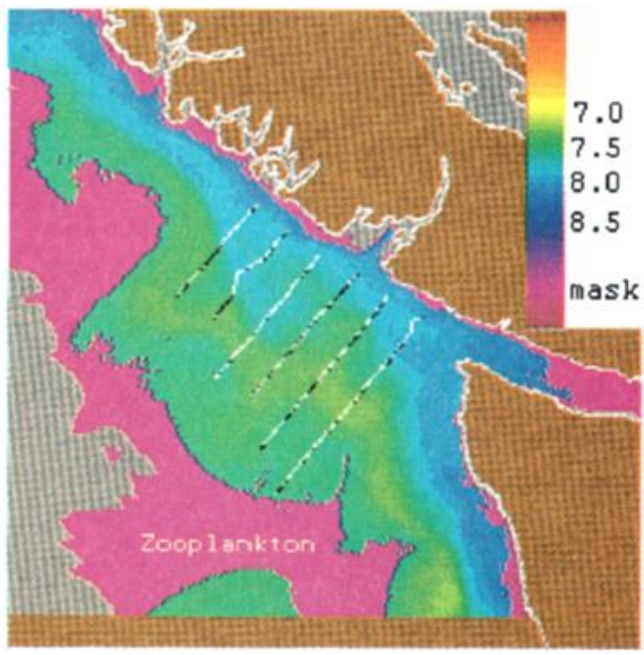

Plate $5 b$

Plate 5 [Thomas and Emery]. "Plankton" image of $(a)$ winter surface chlorophyll distributions and $(b) \log _{e}$ zooplankton distributions constructed from the regression equation of plankton concentration and satellite temperature. Transects are coded to indicate areas where the model differed from sampled concentration by more than the overall rms difference (black) and by less than this difference (white). A pink mask was applied to hydrographic regimes not sampled. 


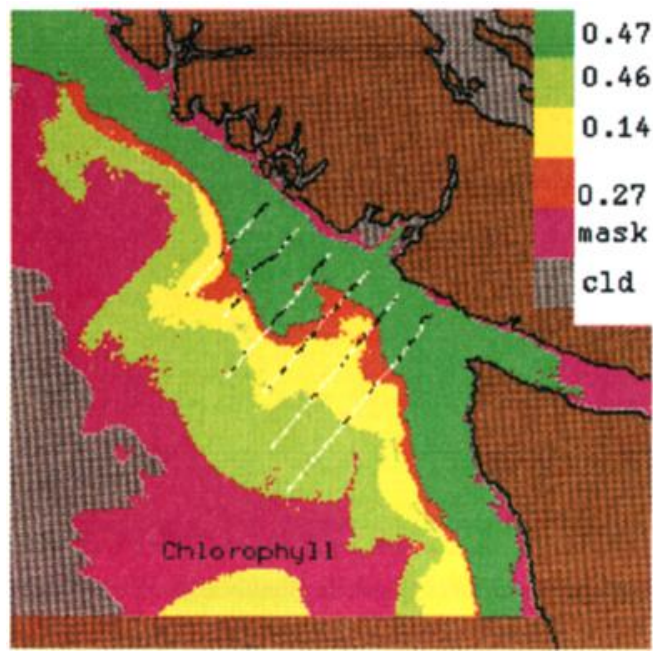

Plate 6a

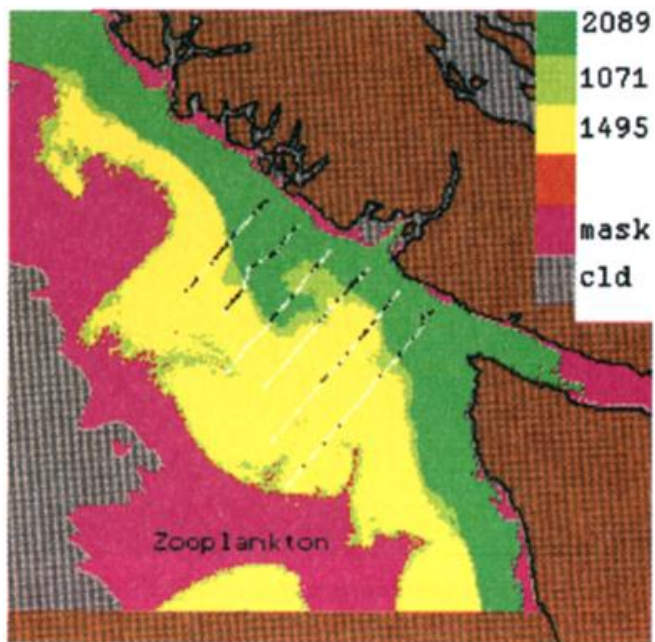

Plate $6 b$

Plate 6 [Thomas and Emery]. "Plankton" image of $(a)$ winter chlorophyll concentration and (b) zooplankton concentration constructed by density slicing in $T-S$ space at temperature and salinity thresholds and assigning mean concentrations to each pixel. Transects are coded to indicate areas where the model differed from sampled concentration by more than the rms difference (black) and by less than the rms difference (white). The pink mask denotes hydrographic regimes outside the study area.

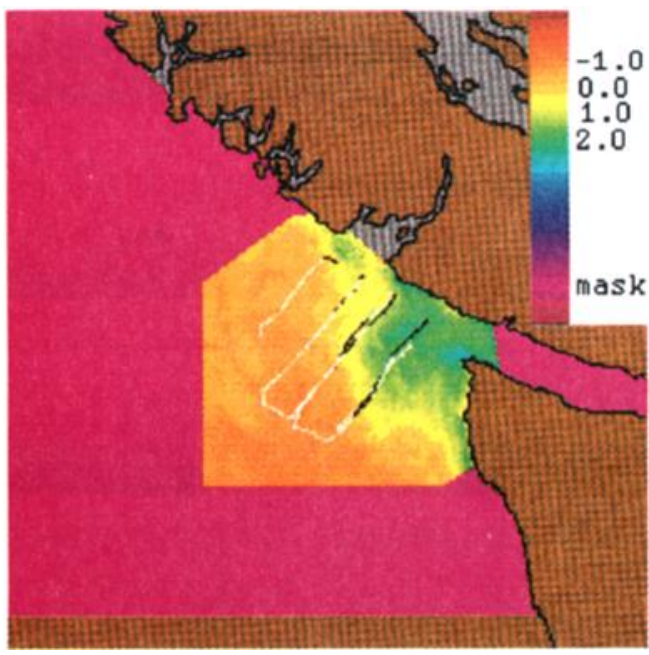

Plate 7 [Thomas and Emery]. "Plankton" image of $\log _{e}$ summer chlorophyll concentrations constructed from the regression equation. Sampling transects are coded to indicate areas where the model differed from sampled concentration by more than the rms difference (black) and by less than the rms difference (white). The pink mask denotes areas outside the study area.

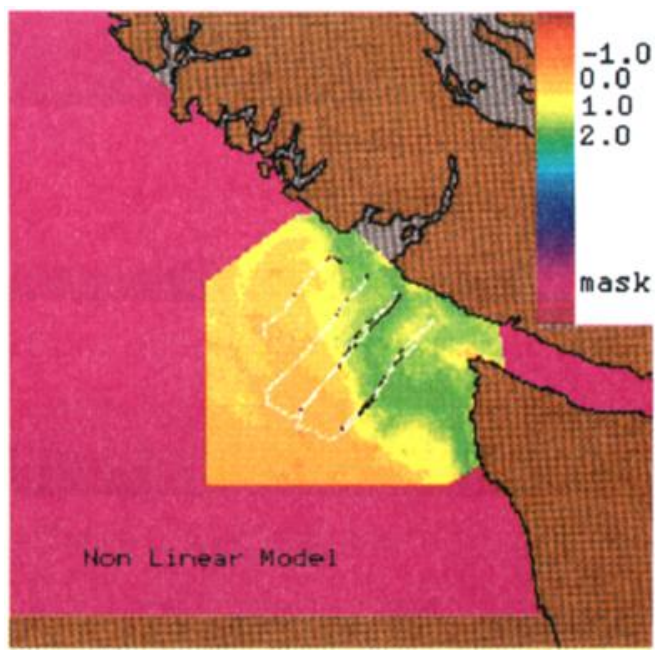

Plate 8 [Thomas and Emery]. "Plankton" image of summer $\log _{e}$ chlorophyll concentrations constructed from the nonlinear regression equation. Transects are coded to indicate areas where the model differed from sampled concentration by more than the rms difference (black) and by less than the rms difference (white). The pink mask denotes areas outside the study area. 